\title{
Depth distribution of soil water sourced by plants at the global scale: a new direct inference approach
}

Anam Amin ${ }^{1}$, Giulia Zuecco ${ }^{1}$, Josie Geris ${ }^{2}$, Luitgard Schwendenmann ${ }^{3}$, Jeffrey J. McDonnell ${ }^{4}$, Marco Borga ${ }^{1}$, Daniele Penna ${ }^{5}$

${ }^{1}$ Department of Land, Environment, Agriculture and Forestry, University of Padova, Italy

${ }^{2}$ School of Geosciences, University of Aberdeen, Aberdeen, Scotland, United Kingdom

${ }^{3}$ School of Environment, University of Auckland, New Zealand

${ }^{4}$ Global Institute for Water Security and School of Environment and Sustainability, University of Saskatchewan, Saskatoon, Canada

${ }^{5}$ Department of Agriculture, Food, Environment and Forestry, University of Florence, Italy

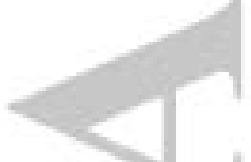

Corresponding author:

Anam Amin

Department of Land, Environment, Agriculture and Forestry, University of Padova (Italy)

via dell'Università 16, 35020 Legnaro (PD), Italy

+390498272674

anam.amin@phd.unipd.it

Running Head: Depth distribution of soil water sourced by plants at the global scale

\section{Abstract}

The depth distribution of soil water contributions to plant water uptake is poorly known. Here we evaluate the main water sources used by plants at the global scale and the effect of climate and plant groups on water uptake variability and depth distribution. We use meta-analysis of published isotopic data $\left(\delta^{2} \mathrm{H}\right.$ and $\left.\delta^{18} \mathrm{O}\right)$ for soil water and xylem water from 65 peer-reviewed papers published between 1990 and 2017.

The isotopic composition of soil water was strongly related to climate. We applied a new direct inference method to quantify the overlap between xylem water and soil water sources used by plants. The median overlap between xylem water and soil water at different depths varied This article has been accepted for publication and undergone full peer review but has not been through the copyediting, typesetting, pagination and proofreading process which may lead to differences between this version and the Version of Record. Please cite this article as doi: $10.1002 /$ eco.2177 
between 28 and $100 \%$, but they were generally $>50 \%$. The shallow soil water overlap $(0-10$ $\mathrm{cm})$ was largest in cold regions $(100 \% \pm 0)$ and lowest at tropical sites (about 28\%). Conversely, the median overlap between xylem water and deep soil water was largest in the arid and the tropical zones (>75\%) and much smaller in the other two climates. Our results suggest that the isotopic composition of xylem water reflects mostly the signature of shallow soil water $(<30 \mathrm{~cm})$ in the cold and the temperate zones, while in the arid and the tropical zones, plants appear to exploit water in deeper soil layers. Our novel simple statistically-based direct inference method performed well in determining these differences in water sources, and can be applied more widely to isotope-based plant water uptake studies.

Keywords: xylem water; soil water; stable isotopes; deuterium excess; global scale; metaanalysis; climate; direct inference.

\section{Introduction}

Transpiration of terrestrial vegetation is a dominant force in the global water cycle, accounting for $60-80 \%$ of total evapotranspiration fluxes on land (Schlaepfer et al., 2014; Schlesinger \& Jasechko, 2014). Transpiration is a major determinant of local microclimate and precipitation patterns and has a direct impact on water balance and streamflow regimes (Andréassian, 2004; Laurance, 2007). Given the important role of plant transpiration in the hydrological cycle, a more detailed understanding of plant water uptake and ecohydrological interactions between plants and soil water is crucial for developing effective land surface models and sustainable water use strategies.

The stable isotopes of hydrogen and oxygen $\left({ }^{2} \mathrm{H}\right.$ and $\left.{ }^{18} \mathrm{O}\right)$ are effective tools to determine the proportions of water sources to plant transpiration. Due to their conservative nature through soils and their occurrence in the water molecule, stable isotopes are increasingly used for tracing water fluxes in ecohydrological and other interdisciplinary studies (Penna et al., 2018; Scandellari \& Penna, 2017). The quantification of the main water sources for plant transpiration based on isotopic tracers is typically carried out through a graphical inference method (Brunel, Walker, \& Kennett-Smith, 1995), two-end-member mixing models (e.g., Thorburn \& Walker, 1993) or statistically-based multi-source mixing models (e.g., Schwendenmann, Pendall, Sanchez-Bragado, Kunert, \& Hölscher, 2015). The graphical inference method defines the mean root water uptake depth as the soil depth where the isotopic composition of soil water is most similar to or equals the one of xylem water. Basically, this approach represents the plant 
root system as one unique root (Rothfuss \& Javaux, 2017). IsoSource (Phillips \& Gregg, 2003) is a widely used linear mixing model based on a mass balance equation (recent examples are Jia, Liu, Chen, \& Yu, 2017; Zhu, Zhang, Gao, Qi, \& Xu, 2016). Nowadays, statistical Bayesian mixing models such as SIAR (Parnell et al., 2013), MixSir, and MixSIAR (Moore \& Semmens, 2008) are gaining popularity (e.g., Beyer, Hamutoko, Wanke, Gaj, \& Koeniger, 2018). For a review and intercomparison of these methods the reader is referred to Rothfuss \& Javaux (2017). Bayesian isotope mixing models have the advantage of providing uncertainties of the estimated fractions of water sources and provide an optimal solution rather than a range of feasible solutions (Rothfuss \& Javaux, 2017). However, a common underlying assumption of these approaches is that all water sources accessed by plant roots are adequately sampled and that the tracer signature is conserved through the mixing processes. But in field studies, sampling all potential water sources is not always practical or possible, creating potential bias in the mixing model estimation of a given plant water source. Therefore, new methods that allow for robust quantification of water sources accessed by plants and that can be distinctly sampled are needed.

In many cases, the primary source of plant transpiration is soil water extracted from different depths by vegetation through roots (Asbjornsen et al., 2011; Gardner \& Ehlig, 1963). Plants can access shallow and deep soil water, as well as groundwater with a tendency to prioritize the use of stable and continuous water sources (Zhao \& Wang, 2018), at least in regions where some sources are continuously available. Several studies based on an isotope approach and focusing on the identification of different water sources accessed by plants have been conducted at individual sites in many regions of the world and on different species (e.g., to name a few recent studies, Allen, Kirchner, Braun, Siegwolf, \& Goldsmith, 2019; Chi, Zhou, Yang, Li, \& Zheng, 2019; Dubbert, Caldeira, Dubbert, \& Werner, 2019; Evaristo et al., 2019; Nie et al., 2019; Oerter, Siebert, Bowling, \& Bowen, 2019; Qiu et al., 2019). Recent metaanalyses assessed plant water sources across different biomes and species (Evaristo, Jasechko, \& McDonnell, 2015; Evaristo \& McDonnell, 2017a; Evaristo \& McDonnell, 2017b; Barbeta $\&$ Peñuelas, 2017).

Despite these meta-analyses and the notable number of studies focussing on the quantification of water sources for tree transpiration in different parts of the world, knowledge on global scale estimates of soil water sources at different depths is still missing. Thus far, global metaanalyses have not quantified the depths of soil water contributions to plant water uptake. 
Indeed, the depth distribution (from the soil surface to the water table) is the key missing link to perhaps reconcile some of the disparity in results from different groups. Here we analyse isotope data extracted from 65 peer-reviewed papers published between 1990 and 2017. We propose a new direct inference method that can approximate the proportion of water sources to root water uptake even if one or more sources are missing. We use this new approach to evaluate the main water sources used by plants around the world and to quantify explicitly the depth distribution of soil water uptake and its relation to climate and plant group.

Specifically, our work aims to answer the following questions:

1) To what extent does the isotopic composition of xylem water reflect that of soil water for different plant groups across the globe?

2) What is the depth distribution of this source water?

3) How does climate and plant groups control these patterns?

\section{Materials and methods}

\subsection{Literature selection and data extraction}

We based our global meta-analysis on isotope data extracted from 65 peer-reviewed papers published between 1990 and the end of 2017 that used both stable isotopes of water $\left(\delta^{2} \mathrm{H}\right.$ and $\left.\delta^{18} \mathrm{O}\right)$ for ecohydrological studies. We performed searches in Web of Science, Scopus, and Google Scholar using different combinations of the following keywords: "water uptake", "xylem", "soil water", "stable isotopes", "hydrogen", "oxygen"). Of the returned papers, we considered only those that reported both $\delta^{18} \mathrm{O}$ and $\delta^{2} \mathrm{H}$ data in soil water at different soil depths, and in xylem water. Our returns included 25 and 37 of the 47 and 138 papers in Evaristo, Jasechko, McDonnell (2015) and Evaristo \& McDonnell (2017b) and 7 of the 35 papers examined in Barbeta \& Peñuelas (2017).

We excluded studies that did not report both isotopes or did not include soil water. Stable isotope data reported in the original papers were extracted either directly from tables or the text, or through the data extraction tool Graph Data Extractor (Matthews, 2017) or obtained from digital repositories. The database includes isotope data from soil water $(n=5328)$ and xylem water $(\mathrm{n}=2579)$ from 77 study sites (some papers reported data from more than one site, so the number of study sites is larger than the numbers of screened papers) belonging to four different climate zones of the world, according to Köppen classification (Peel, Finlayson, \& McMahon, 2007) (Fig. 1 and Table S1). For each paper we collected additional information 
including the geographical coordinates of the study area, elevation, plant group or species, and soil depths reported by authors of the original papers. In case some of this information was missing, we obtained it through online resources. Coordinates were extracted via Google Earth, elevation via GPS Visualizer (Schneider, 2017), and the distinction between gymnosperms and angiosperms via The Plant list (2013).

To evaluate the effects of different environmental factors on the isotopic composition of soil and xylem water, we compiled the following information in a GIS environment: Mean Annual Temperature (MAT) in ${ }^{\circ} \mathrm{C}$ obtained from Esri ArcGIS online map derived from WorldClim version 1.4 (Hijmans, Cameron, Parra, Jones, \& Jarvis, 2005) for the period 1950-2000 (30 arc seconds or approx. $1 \mathrm{~km}$ at equator); Global Aridity Index (UNEP, 1997) values extracted from a dataset provided by Consortium for Spatial Information (CGIAR-CSI) (Trabucco \& Zomer, 2009) at $0.0083^{\circ}$ spatial resolution. We chose to retrieve MAT and Global Aridity Index values of the study sites from global databases because not all the papers reported all the characteristics and we wanted to have a consistent database avoiding different classifications.

\subsection{Statistical tests and direct inference method}

To compare xylem water and soil water samples from the four climate zones we computed the deuterium-excess (d-excess) for each data point following Dansgaard (1964):

$\mathrm{d}-$ excess $=\delta D-8 \times \delta^{18} O$

d-excess is interpreted as an index for the characterization of non-equilibrium conditions during global evaporation-condensation process. We used d-excess instead of line-conditioned excess (Landwehr \& Coplen, 2006) because Local Meteoric Water Lines and/or the isotopic composition of local precipitation were not available for all the individual study sites. Therefore, for consistency in the data analysis we computed d-excess.

All extracted isotopic data of soil and xylem waters were tested for normality and revealed that the data were not-normally distributed (Shapiro-Wilk normality test, $\mathrm{p}<0.01$ ). All subsequent statistical analyses to compare samples were thus performed using non-parametric tests. These included the Mann-Whitney rank sum test (Hollander \& Wolfe, 1999) to compare the isotopic values of xylem water and soil water within each climate zone, and the Kruskal-Wallis oneway analysis of variance test to assess differences in the isotopic composition of xylem and soil waters across the four climate zones, plant groups, and soil depths. Spearman rank 
correlation analyses were used to assess the strength of the correlation between MAT, elevation of the study sites and Global Aridity Index with $\delta^{18} \mathrm{O}, \delta^{2} \mathrm{H}$ and d-excess of soil water (Table 2) and xylem water (Table 3).

We quantified the contributions of water sources (i.e., soil water at different depths) to root water uptake at the global scale using a new isotope-based direct inference method. The only assumption underlying this method is that the isotopic signature of xylem water is conserved during the water uptake (i.e., no fractionation during transport) and reflects the contribution of the different water sources. For each study site, we plotted all the data in a dual-isotope space, and drew ellipses based on 99\% confidence intervals (Friendly, Monette, \& Fox, 2013) for each source (here the soil water at different depths) and xylem water (Fig. 2), using the R function called covEllipses (Fox, Friendly, \& Monette, 2018). For the determination of the ellipse parameters, we applied two algorithms to remove outliers, including the minimum volume ellipsoid (MVE; Van Aelst \& Rousseeuw, 2009) and the minimum covariance determinant (MCD; Croux \& Haesbroeck, 1999; Rousseeuw \& Van Driessen, 1999), in order to provide information about the uncertainty of the estimates. Furthermore, the application of the two different methods for the detection of the outliers allowed for the analysis of the sensitivity of our results for a given algorithm. We then counted the number of xylem water samples falling in the intersection space (graphically overlapping) between the ellipse of the xylem water samples and the ellipses of the different potential water sources as follows:

$$
\text { overlap }(\%)=\frac{n_{\text {water source }}}{n_{\text {total }}-n_{\text {out }}} \times 100
$$

where $n_{\text {water source }}$ represents the number of xylem water samples falling in the intersection space with a given water source, $n_{\text {total }}$ represents the total number of xylem water samples, and $n_{\text {out }}$ is the number of xylem water samples falling outside the xylem water ellipse (Fig. 2). As the sample size for some study sites was small, we considered only those water sources with a minimum of four data points for the application of our inference method. We found that applying this method when less than four data points were available led to biased results compared to the ones obtained when more than four data points were available. This reduced the number of study sites from 77 to 56 for the computation of the overlap of soil water and xylem water. The key difference between this new isotope-based direct inference method and more commonly used mixing models is that the contributions here do not add up to one (or 
$100 \%)$ of the water uptake. Hence, the results do not provide proportional water use directly, but instead offer a more transparent approach towards similarities between different water sources and xylem water. As it eliminates issues with potentially unsampled water sources and the uncertainties associated with best-solution mixing models, comparisons between sites are therefore more straightforward.

\section{Results}

\subsection{Isotopic composition of xylem and soil waters in different climate zones}

Soil and xylem waters had a large range of isotopic variability in all four climate zones (Fig. $3)$. The median isotopic compositions of soil and xylem waters were enriched in heavy isotopes in the tropical zone $\left(\delta^{2} \mathrm{H}=-34.7 \%\right.$ o (soil), $-28.1 \%$ (xylem); $\delta^{18} \mathrm{O}=-5.20 \%$ (soil), $-3.88 \%$ o (xylem)) and most depleted in the cold zone $\left(\delta^{2} \mathrm{H}=-78.2 \%\right.$ (soil), $-95.6 \%$ (xylem); $\delta^{18} \mathrm{O}=-$ $10.27 \%$ (soil), $-11.74 \%$ (xylem)) (Table S2). Soil and xylem waters in the arid and the temperate zones had similar median isotopic compositions, and intermediate between the tropical and the arid zones.

The isotopic composition of xylem water reflected that of soil water quite well in all climates, especially in the tropical zone (Fig. 3 and S1).

Deviations of soil water from the GMWL were particularly large in the arid zone, followed by the temperate and cold zone, and very small in the tropical zone. In addition, in the temperate and the arid zones, soil water was often more evaporated than xylem water, particularly for soil water samples which were very enriched in heavy isotopes (Fig. 3 and S1). The deviation of soil water from the GMWL was related to the sampling depth, but there were differences across the climate zones (Fig. 4). In the tropical zone, all the soil water samples plotted together along the GMWL, except for few samples of soil water at the 0-10 cm depth probably affected by evaporation (very low d-excess values). In the temperate and the cold zones, soil water sampled at $30-50 \mathrm{~cm}$ and $>50 \mathrm{~cm}$ depths plotted together and quite close to the GMWL, while shallower soil water tended to deviate more from the GMWL. In the arid zone, the soil water sampled at $>50 \mathrm{~cm}$ depth was the least affected by evaporation, while almost all the soil water from shallower layers plotted well below the GMWL (Fig. 4). However, some discrepancies were observed due to the isotopic variability among the study sites.

We found a significant difference in the isotopic composition (for both isotopes) of soil water at different depths separately tested for the four climate zones (Kruskal-Wallis one-way analysis of variance test, $\mathrm{p}<0.001$ and $\mathrm{p}<0.001$ for both $\delta 2 \mathrm{H}$ and $\delta 18 \mathrm{O}$ ). 


\subsection{Overlap between xylem water and water sources}

The dual-isotope plots highlighted the large overlap between the isotopic composition of soil water and xylem water across climate zones (Fig. 3 and S1). The median overlap between xylem water and soil water at $0-10 \mathrm{~cm}$ depth decreased from the cold zone $(100 \pm 0 \%$, representing median \pm median absolute deviation, for the computations with both the MCD and MVE algorithms; Fig. 5) to the temperate (58 $\pm 25 \%$ and $53 \pm 20 \%$ for MCD and MVE, respectively), the arid ( $45 \pm 16 \%$ for both MCD and MVE) and the tropical zone $(28 \pm 14 \%$ and $29 \pm 14 \%$ for MCD and MVE, respectively). The median overlap between xylem and soil waters at $10-30 \mathrm{~cm}$ varied between $35 \pm 17 \%$ using MCD (or $34 \pm 16 \%$ for MVE) in the tropical zone and $84 \pm 16 \%$ for MCD ( $85 \pm 15 \%$ for MVE) in the temperate zone (Fig. 5). The median overlap between xylem and soil waters at 30-50 cm depth was particularly large in the arid zone (96 $\pm 4 \%$ for MCD, $88 \pm 4 \%$ for MVE), while the overlap between xylem and soil waters at $>50$ cm depth was the largest in the tropical zone ( $83 \pm 8 \%$ for MCD, $77 \pm 10 \%$ for MVE) followed by the arid climate $(77 \pm 2 \%$ for MCD, $77 \pm 6 \%$ for MVE).

These results suggest that the isotopic composition of xylem water tends to be very similar to that of shallow soil water (0-10 and 10-30 cm depths) in the temperate and the cold zones, while in the arid and the tropical zones the isotopic signature of xylem water reflects more the composition of deep soil water (30-50 and $>50 \mathrm{~cm}$ depths).

The median absolute deviations of the overlaps were quite variable across the climate zones and the water sources (Fig. 5). They were quite large especially in the cold zone, indicating a high variability in the overlap across the few study sites. However, the variability in the overlap across the study sites did not significantly affect the overall interpretation of the strong similarity in the isotopic composition of xylem water and soil water and the differences found across the climate zones. The differences in the overlaps between xylem water and soil water at different depths resulting from the application of the two algorithms (MCD and MVE) varied between $-1 \%$ and $+1 \%$ for $61 \%$ of the cases, suggesting that there was a small sensitivity of the results to the choice of the algorithm used for detecting outliers and drawing the ellipses.

\subsection{Variability in the isotopic composition of xylem and soil waters among different climate zones}

We found a significant difference in the isotopic composition (for both $\delta^{2} \mathrm{H}$ and $\delta^{18} \mathrm{O}$ ) of xylem and soil waters across the four climate zones (Kruskal-Wallis one-way analysis of variance test, $\mathrm{p}<0.001$ and $\mathrm{p}<0.001$ for both $\delta^{2} \mathrm{H}$ and $\delta^{18} \mathrm{O}$ of xylem water and soil water, respectively) (Fig. 3). The median d-excess of soil water increased (i.e. became less negative) with increasing 
soil depth in all climate zones (Table 1). Except for the tropical zone, the soil water at $0-10 \mathrm{~cm}$ depth had a negative median d-excess, while the deeper soil water had a positive median dexcess in all the climates, but the arid zone. This indicates that evaporative fractionation processes were strongest in the arid zone, where even the median d-excess of soil water at $>50$ cm depth was negative and lower than the median d-excess of shallow soil water in the tropical and the cold zones (Table 1).

The classification of the study sites based on the Global Aridity Index showed that xylem and soil waters in the most arid study sites had the most negative d-excess, suggesting the influence of relatively strong evaporation processes (Fig. 6). An overall increasing trend in d-excess was observed for both xylem and soil waters from the arid \& hyper-arid class to the humid class. Xylem water had lower d-excess than soil water in most of the Global Aridity Index classes. However, for the arid \& hyper-arid class, where sample size was smaller and variability generally larger, this pattern was not observed. Only in the humid class more than $50 \%$ of soil water and xylem water samples had positive d-excess values (Fig. 6).

Both soil water (Table 2) and xylem water (Table 3) $\delta^{2} \mathrm{H}$ and $\delta^{18} \mathrm{O}$ values were strongly positively correlated with mean annual temperature. $\delta^{2} \mathrm{H}$ and $\delta^{18} \mathrm{O}$ of both xylem and soil waters also had a significant negative correlation with elevation of the study sites (Tables 2 and 3), and a positive but weaker correlation with the Global Aridity Index.

d-excess of soil and xylem waters had the strongest positive correlation with the Global Aridity Index (Table 2 and 3), confirming that evaporative fractionation was stronger in the arid than the humid study sites. MAT and elevation also had significant correlations with d-excess of soil water (Table 2) and xylem water (Table 3), but they were weak particularly for soil water.

\subsection{Variability in the isotopic composition of xylem water for different plant groups}

The isotopic compositions of xylem water in angiosperms and gymnosperms were similar in the cold zone (Mann-Whitney rank sum test, $\mathrm{p}>0.05$ for both $\delta^{18} \mathrm{O}$ and $\delta^{2} \mathrm{H}$ ). We found a significant difference in the isotopic composition of xylem water of angiosperms and gymnosperms in the arid zone (Mann-Whitney rank sum test, $\mathrm{p}<0.001$ for both $\delta^{2} \mathrm{H}$ and $\delta^{18} \mathrm{O}$ ) and the temperate zone (Mann-Whitney rank sum test, $\mathrm{p}<0.001$ for $\delta^{18} \mathrm{O}$ and $\mathrm{p}<0.05$ for $\delta^{2} \mathrm{H}$ ). The deviation of xylem water samples from the GMWL was evident and different for angiosperms and gymnosperms in the arid zone, while xylem water samples of angiosperms and gymnosperms plotted together and deviated similarly from the GMWL in the temperate and the cold zones (Fig. 7).

This article is protected by copyright. All rights reserved. 
The median d-excess was very negative for xylem water samples in the arid zone, with lower values for gymnosperms compared to angiosperms (Table 1). In the temperate zone, the median d-excess of xylem water was slightly lower for angiosperms than gymnosperms, while in the cold zone, stronger evaporation processes determined the lower median d-excess for angiosperms than gymnosperms. We found statistically significant differences in the d-excess of xylem water of angiosperms and gymnosperms in all the three climates (Mann-Whitney rank sum test, $\mathrm{p}<0.001$ in the arid and the temperate zones, $\mathrm{p}<0.01$ in the cold zone). Our choice in grouping of plants did not allow for exploring their role in the tropics as all the samples contained data for angiosperms only (Fig. 7 and Table 1).

\section{Discussion}

\subsection{Xylem water isotopic composition reflects soil water uptake from different depths} across the globe

Dual-isotope plots (Fig. 3) and the direct inference approach (Fig. 5) revealed a strong overlap of xylem water and soil water isotopic composition across climate zones. This implies that trees and shrubs across the globe obtain most of their water from soil water. It has to be noted that our findings might be slightly biased towards soil water uptake as groundwater data were not considered in our study (Fig. 5). However, our findings are in line with previous studies and meta-analyses showing that trees across most climate zones predominantly rely on soil water (Bowling, Schulze, \& Hall, 2017; Brooks, Barnard, Coulombe, \& McDonnell, 2010; Evaristo -et al., 2019; Geris, Tetzlaff, McDonnell, \& Soulsby, 2017; Grossiord et al., 2016; Gu et al., 2015; Rose, Graham, \& Parker, 2003; Rossatto, de Carvalho Ramos Silva, Villalobos-Vega, Sternberg, \& Franco, 2012; Wei, Fang, Liu, Zhao, Li, 2013; Yang \& Fu, 2017).

Our results also suggest that trees take up most of their water from the upper soil layers (here: 0-50 cm, Fig. 5). Despite strong fluctuations in soil water availability, several studies have shown that trees obtain a considerable proportion of water from shallower soil layers (Barnard et al., 2010), although the extent of this proportion is highly variable depending on tree species, soil type and environmental conditions. The reliance on water from upper soil layers has been related to higher nutrient availability (Goldsmith et al., 2012; Schwendenmann, Pendall, Sanchez-Bragado, Kunert, \& Hölscher, 2015) and root biomass (February \& Higgins, 2010; Jobbágy \& Jackson, 2001) in these soil layers and rehydration of upper soil due to hydraulic lift under dry conditions (Caldwell, Dawson, \& Richards, 1998). To minimize energy use, plants are likely to extract water from soil layers with highest rooting density assuming the soil is uniformly wet (Adiku, Rose, Braddock, \& Ozier-Lafontaine, 2000), and at the highest 
available water potential (i.e., easiest to withdraw; Gardner, 1960). Moreover, plants can often take up relatively "new" water (Sprenger et al., 2019) although some recent studies showed that water transpired from trees during summer originated from rain that fell during the previous winter (Allen et al., 2019; Brinkmann et al., 2018).

In line with other studies, our findings also show that plants extract water from multiple soil layers (Fig. 5) (Asbjornsen, Shepherd, Helmers, \& Mora, 2008; Le Roux, Bariac, \& Mariotti, 1995; Schwendenmann, Pendall, Sanchez-Bragado, Kunert, \& Hölscher, 2015). Water uptake from deeper soil layers (here: below $50 \mathrm{~cm}$ ) is often reported from arid/semiarid regions (Evaristo \& McDonnell, 2017b) but is also found in areas characterised by pronounced dry seasons (Barbeta \& Peñuelas, 2017). For example, deep rooting (Davidson et al., 2011; Markewitz, Devine, Davidson, Brando, \& Nepstad, 2010) and deep soil water extraction in tropical forests are important mechanisms to sustain growth during the dry season (RestrepoCoupe et al., 2013; Wu et al., 2016). A number of studies suggest that deep root systems are not restricted to trees and shrubs in arid/semiarid and seasonally dry forests (e.g., Pierret et al., 2016). Thus, the role of deep root water uptake across ecosystems may have been underestimated (Pierret et al., 2016). Studies have shown that in very deep soil, some trees can develop deep roots that may access “old” waters (Zhang et al., 2017; Sprenger et al., 2019).

\subsection{Climate has first order effect on the isotopic compositions of xylem and soil waters}

The observed major control exerted by climate on the isotopic composition of xylem and soil water confirmed several ecological studies across different regions (see Werner et al., 2012, and references therein). The climate control was evident via climate zone grouping (Figs. 3-5) and exploring variations in isotopic signatures with climate-related proxies including aridity index (Fig. 6), mean annual temperature (Fig. S2) and elevation (Table 2 and 3; Fig. S2 and S3). Stable water isotope composition of precipitation is strongly related to altitude, temperature and other climate factors (Dansgaard, 1964; Gat, 1996). Therefore, to some extent, the relative differences between isotopic signatures in the various climates found in xylem water and soil water samples reflected those in precipitation. $d$-excess values for soil and xylem waters both decreased as a function of aridity index values, whereby most negative d-excess values were found in the arid climate zone while least negative or even positive values were found in humid regions (Fig. 6; Table 2 and 3). High potential evapotranspiration, relatively low soil water content (Allison, Barnes, \& Hughes, 1983) and low relative humidity (Cappa,

Hendricks, DePaolo, \& Cohen, 2003; Gibson, Birks, \& Edwards, 2008) are all factors that 
enhance non-equilibrium fractionation during evaporation and are typically most pronounced for arid regions.

The evaporation front in the soil profile was also markedly different between climate zones and again most distinct for the arid regions. Our results showed that overall, deep $(>50 \mathrm{~cm})$ soil water was less deviated from the GMWL (Fig. 4). The d-excess profile changes with depth were most marked in the arid, then temperate and cold zone, while little variations were found for the tropical zone (Table 1). Using data from 25 sites across the world, Sprenger, Leistert, Gimbel, \& Weiler (2016) revealed that the evaporative fractionation effects were generally limited to the upper $30 \mathrm{~cm}$ of the soil, but that this effect was climate dependent. Deep progression fronts up to 2-3 m have been reported for sites in arid climates (e.g., Beyer, Hamutoko, Wanke, Gaj, Koeniger, 2018; Singleton, Sonnenthal, Conrad, DePaolo, \& Gee, 2004), while in tropical climates a clear vertical gradient in the soil water isotopic signal is usually only observed under pronounced dry seasons (Querejeta, Estrada-Medina, Allen, \& Jiménez-Osornio, 2007). In tropical regions, the high humidity (Goller et al., 2005; Good, Noone, \& Bowen, 2015) and typically dense vegetation cover (Dubbert, Cuntz, Piayda, Maguás, \& Werner, 2013) can both contribute to relatively low soil evaporation.

Xylem water in the arid and cold zones had lower d-excess values (Table 1). This is consistent with Bertrand et al. (2014), Yang \& Fu (2017) and Zhu, Wang, Mao, Zheng, \& Xu (2014) and values reported for the tropical and temperate zone (Goldsmith et al., 2012; Hervé-Fernández et al., 2016; Rosado, De Mattos, \& Sternberg, 2013). The patterns between climate zones largely reflect those found in the soil water and indicate more fractionation with aridity. However, the result for the cold zone is quite different, with a more extreme difference between the soil and xylem water found in this region. As observed elsewhere and across climate zones (e.g., Evaristo, Jasechko, McDonnell, 2015) soil water often shows more fractionated isotope signatures than xylem water, with xylem water reflecting water uptake from a blend of sources. However, in our analyses for the cold climate zone, none of the soil water depths showed similarly strong negative median d-excess values as the xylem water (Table 1). In addition to possible improper sampling, i.e., not sampling the right water pool (Penna et al., 2018), one explanation could be that plant source water in cold regions might not be adequately represented by the soil water samples alone, or that soil water in cold climates is recharged by (non-fractionated, and isotopically light) snowmelt. Isotope signatures in soil and xylem water always reflect the combined effects of source variation, mixing, and fractionation (Benettin et 
al., 2018). By bulking all soil water across depths and plant water across groups, some of the patterns may have also come out more extreme than as for a per-site comparison of samples across soil depth and plant groups.

\subsection{Effect of plant groups on isotopic composition of xylem water}

We found significantly higher xylem water $\delta^{2} \mathrm{H}$ and $\delta^{18} \mathrm{O}$ values in angiosperms than gymnosperms in the arid zone (Fig. 7). The most enriched xylem water across all studies was measured in Guiera senegalensis, a perennial woody shrub found across the Sahel (Brunel, Walker, Dighton, \& Monteny, 1997). Xylem water of Guiera senegalensis was often higher than the highest soil water $\delta^{2} \mathrm{H}$ and $\delta^{18} \mathrm{O}$ values (Brunel, Walker, Dighton, \& Monteny, 1997). Evaporative enrichment of xylem water has been associated with leaflessness (Ellsworth \& Sternberg, 2015; Phillips \& Ehleringer, 1995) and periods of limited sap flow (Martín-Gómez,

Serrano, \& Ferrio, 2017) which may partly explain higher xylem water $\delta^{2} \mathrm{H}$ and $\delta^{18} \mathrm{O}$ values in angiosperms across the arid zone.

Furthermore, differences in plant functional traits between angiosperms and gymnosperms (e.g., photosynthetic capacity, leaf phenology, transpiration rate, hydraulic capacity, water use efficiency, rooting pattern) (Augusto, Davies, Delzon, \& De Schrijver, 2014; Cernusak, Winter, Aranda, \& Turner, 2008) may contribute to differences in xylem water isotopic composition. For example, angiosperms tend to have higher leaves transpiration rates (Hetherington \& Woodward, 2003) and are less drought resistant than gymnosperms (Choat et al., 2012). To meet the water demand, plants in arid systems sometimes rely on water from upper soil layers which is characterised by higher $\delta^{18} \mathrm{O}$ and $\delta^{2} \mathrm{H}$ values due to high evaporation especially during summer (West, Hultine, Burtch, \& Ehleringer, 2007; Rose, Graham, \& Parker, 2003).

However, most studies showed that water isotope composition and water uptake patterns tend to be species- and ecosystem- specific (e.g., Asbjornsen, Shepherd, Helmers, \& Mora 2008; Goldstein et al., 2008; Phillips \& Ehleringer, 1995; Weltzin \& McPherson, 1997; Williams \& Ehleringer, 2000). For example, various gymnosperms growing in a woodland in southern Utah showed differences in their water uptake. Pinus edulis acquired water from both shallow and deep water sources, whereas the shrub Juniperus osteosperma used shallow water when water was available in the spring and shifted to deeper sources for the remainder of the growing season, and Pinus taeda obtained water predominantly from the upper soil profile (Retzlaff, Blaisdell, \& Topa, 2001; West, Hultine, Burtch, \& Ehleringer, 2007). 


\subsection{Limitations of the study}

Our findings can be considered statistically robust due to the large number of samples (> 5000 for soil water and $>2500$ for xylem water, Table S2) and of plant species (> 170) included in this meta-analysis. Nevertheless, we acknowledge some limitations that may impact the interpretation of the results. First, the study sites are unevenly distributed among the four climatic zones, with the highest number in the temperate zone and the smallest number in the tropical zone. Hence, areas characterized by particular climatic conditions within the arid, tropical and cold zones are underrepresented, and more studies would be necessary to include in order to make the global analysis of plant water uptake more generalizable.

Second, coexisting plant species may have different ecohydrological niches that we were not able to adequately represent in this study, other than simply separating angiosperms from gymnosperms. Similarly, different species, or even the same species but of different age, size and/or growing in diverse environmental conditions, are likely characterized by different root depths that might reach different soil depths and access different water sources, therefore hampering an equal comparison in the analysis of plant water uptake (e.g., Bargués Tobella et al., 2017). However, the large sample size of our study may make the general pattern reasonably valid.

Third, most papers did not collect samples of soil and xylem waters at the same time, or did not specify the collection time: this limits the assessment of the possible differences between the isotopic composition of xylem water and of its potential water sources in the light of the lag time between root water absorption and transport to the leaves, that can take days to weeks or even months (e.g., Allen, Kirchner, Braun, Siegwolf, \& Goldsmith, 2019; Brinkmann et al., 2018). However, given the large number of samples taken from different species and different climate regions these possible differences are likely smoothed out.

Fourth, some issues intrinsic in meta-analyses, particularly at the global scale, exist, and they can limit more vigorous comparison of results. Of particular importance is the adoption of different sampling protocols for xylem water (e.g., samples collected from twigs or from the stem or from wood cores), and soil material (e.g., Goldsmith et al. (2019) showed heterogeneity of isotopic signal due to spatial variability of soil water samples) and different water extraction methods both for xylem water and soil water (Table 4). Several studies have reported that different water extraction techniques can return different isotopic composition from the same 
sample (see the comprehensive review by Millar, Pratt, Schneider, \& McDonnell, 2018 for plant water samples, and comments in Penna et al., 2018), and that even the same technique carried out in different laboratories can have a strong impact in determining the isotopic composition of soil water (Orlowski et al., 2018). Therefore, uncertainties associated to the different water extraction techniques can possibly impact our findings. However, this uncertainty is difficult to quantify due to the variety of extraction methods (Table 4) and settings reported in the collected papers, and the lack, in many papers, of any information on the uncertainty related to the application of the extraction method, and, more in general, the lack of a common procedure. With these conditions, it is almost impossible to incorporate a reliable uncertainty estimate into the algorithms used in our direct inference approach (Fig. 2 and 5). Moreover, there might be other factors that could affect the isotopic composition of soil water and that we were not able to consider, often because this information is not reported in the reviewed papers. For instance, nutrients tend to be concentrated in the upper soil and can lead to temporally plastic root water uptake behaviour and hence variations in the isotopic composition of xylem water even in plants with access to groundwater (Dubbert, Caldeira, Dubbert, \& Werner, 2019). Organic matter can prevent or reduce soil evaporation and increase water retention (Ankenbauer \& Loheide, 2017; Saxton \& Rawls, 2006; Schoonover \& Crim, 2015) and influence fractionation effect of soil water as well as soil microbial respiration (Stoll, 2014).

Finally, we must note that differences exist in the estimates of soil water uptake reported in the original studies included in the database and the estimates derived from our analysis. Differences are not surprising due to intrinsic uncertainty in the different methods applied. The mixing models typically used in the papers we analysed (e.g., IsoSource, MixSIAR) are based on the assumption that all water sources accessed by plant roots are adequately sampled and that the tracer signature is conserved through the mixing processes. However, in field studies, sampling all potential water sources is not always practical or possible, creating potential bias in the mixing model estimation of plant water source. The direct inference method we proposed here is a simple statistically-based method that we applied to compare all data included in the global database. Based on its assumptions, this approach has the advantage to quantitatively assess the contribution of each of the identified water sources even if one or more sources are missing. However, this approach relies on the assumption that no-fractionation occurs at the soil-root interface or within plant woody tissues which is being increasingly questioned (Barbeta et al., 2019). Hence, these results should be used with caution, and extended analyses 
on various plant species and in different climatic contexts are needed to further test this method and to evaluate the differences compared to widely used mixing model results.

\section{Concluding remarks and how to move forward}

Previous global meta-analyses studies have assessed the relative contributions of soil water and groundwater used by various plant species, but have not yet provided estimates of soil water depth contributions to water uptake. As far as we know, this is the first study that evaluated the main water sources used by plants globally and explored the effect of climate and plant groups on water uptake variability. Our meta-analysis was based on the extraction of isotopic data (both $\delta^{2} \mathrm{H}$ and $\delta^{18} \mathrm{O}$ ) from 65 peer-reviewed papers published between 1990 and the end of 2017. The database included isotopic compositions of soil water and xylem water from 77 study sites belonging to four climate zones (i.e., tropical, arid, temperate and cold zone).

The analysis of dual-isotope plots showed that there was a wide overlap between the isotopic composition of xylem water with that of soil water, indicating soil water as the main water source for plant transpiration. We developed and applied a new direct inference method to quantitatively assess the overlapping proportions between xylem water and water sources potentially exploited by plants. The median overlaps between xylem and soil waters at different depths were generally above $50 \%$. We also found that climate acts as the main driver of the isotopic composition of soil water. Our results suggest that the isotopic composition of xylem water tends to be very similar to that of shallow soil water (0-10 and $10-30 \mathrm{~cm}$ depths) in the temperate and the cold zones, while in the arid and the tropical zones the isotopic signature of xylem water reflects more the composition of deep soil water $(30-50$ and $>50 \mathrm{~cm}$ depths)

The proposed new direct inference method to quantify overlaps between xylem water and various water sources has a high potential due to its intrinsic ease of application and because it is an information-based method that can be used to determine the main water sources used by plants for transpiration. However, future research should aim at testing the new direct inference method across more study sites and comparing it to other methods (e.g., Bayesian mixing models) for the quantification of the contribution of water sources to transpiration.

Finally, our research suggests that further ecohydrological research should be performed in tropical and arid zones because of the few studies published in these regions so far. Collection of soil water samples at different depths to connect in time and space to corresponding xylem 
water samples is urgently needed to build a more robust dataset for future analysis of transport processes within the soil-plant-atmosphere continuum.

Author contributions: DP, GZ and MB suggested the main objective and the meta-analysis approach. DP proposed the direct inference method and developed it with GZ. AA performed the literature search, compiled the database and did the data analyses. JG and LS contributed to refining the objectives and data analyses and LS provided additional data. AA, GZ, DP, LS and JG wrote the manuscript, JJM and MB edited and revised it.

Acknowledgements: GZ acknowledges the financial support provided by Fondazione Cariparo (research project "Ecohydrological Dynamics and Water Pathways in Forested Catchments", Bando Starting Grants 2015). We also thank the associate editor and two anonymous reviewers for their constructive comments, which helped improving the manuscript.

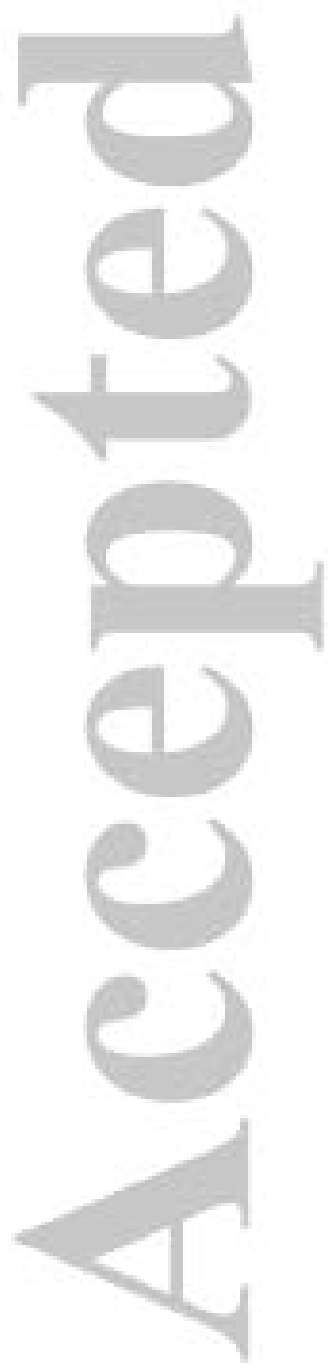

This article is protected by copyright. All rights reserved. 


\section{REFERENCES}

Adiku, S. G. K., Rose, C. W., Braddock, R. D., \& Ozier-Lafontaine, H. (2000). On the simulation of root water extraction: examination of a minimum energy hypothesis. Soil Science, 165(3), 226-236. https://doi.org/10.1097/00010694-200003000-00005

Allen, S. T., Kirchner, J. W., Braun, S., Siegwolf, R. T. W., \& Goldsmith, G. R. (2019). Seasonal origins of soil water used by trees. Hydrology and Earth System Sciences, 23(2), 1199-1210. https://doi.org/10.5194/hess-23-1199-2019

Allison, G. B., Barnes, C. J., \& Hughes, M. W. (1983). The distribution of deuterium and $18 \mathrm{O}$ in dry soils 2. Experimental. Journal of Hydrology, 64(1), 377-397. https://doi.org/10.1016/0022-1694(83)90078-1

Andréassian, V. (2004). Waters and forests: from historical controversy to scientific debate. Journal of Hydrology, 291(1), 1-27. https://doi.org/10.1016/j.jhydrol.2003.12.015

Ankenbauer, K. J., \& Loheide, S. P. (2017). The effects of soil organic matter on soil water retention and plant water use in a meadow of the Sierra Nevada, CA. Hydrological Processes, 31(4), 891-901. https://doi.org/10.1002/hyp.11070

Asbjornsen, H., Goldsmith, G. R., Alvarado-Barrientos, M. S., Rebel, K., Van Osch, F. P., Rietkerk, M., ... Dawson, T. E. (2011). Ecohydrological advances and applications in plant-water relations research: a review. Journal of Plant Ecology, 4, 3-22. https://doi.org/10.1093/jpe/rtr005

Asbjornsen, H., Shepherd, G., Helmers, M., \& Mora, G. (2008). Seasonal patterns in depth of water uptake under contrasting annual and perennial systems in the Corn Belt Region of the Midwestern U.S. Plant and Soil, 308, 69-92. https://doi.org/10.1007/s11104-0089607-3

Augusto, L., Davies, T. J., Delzon, S., \& De Schrijver, A. (2014). The enigma of the rise of angiosperms: can we untie the knot? Ecology Letters, 17(10), 1326-1338. https://doi.org/10.1111/ele.12323

Barbeta, A., Jones, S. P., Clavé, L., Wingate, L., Gimeno, T. E., Fréjaville, B., ... Ogée, J. (2019). Unexplained hydrogen isotope offsets complicate the identification and quantification of tree water sources in a riparian forest. Hydrology and Earth System Sciences, 23(4), 2129-2146. https://doi.org/10.5194/hess-23-2129-2019 
Barbeta, A., \& Peñuelas, J. (2017). Relative contribution of groundwater to plant transpiration estimated with stable isotopes. Scientific Reports, 7(1), 10580. https://doi.org/10.1038/s41598-017-09643-X

Bargués Tobella, A., Hasselquist, N. J., Bazié, H. R., Nyberg, G., Laudon, H., Bayala, J., \& Ilstedt, U. (2017). Strategies trees use to overcome seasonal water limitation in an agroforestry system in semiarid West Africa. Ecohydrology, 10(3), e1808. https://doi.org/10.1002/eco.1808

Barnard, H. R., Graham, C. B., Van Verseveld, W. J., Brooks, J. R., Bond, B. J., \& McDonnell, J. J. (2010). Mechanistic assessment of hillslope transpiration controls of diel subsurface flow: a steady-state irrigation approach. Ecohydrology, 3(2), 133-142. https://doi.org/10.1002/eco.114

Benettin, P., Volkmann, T. H. M., von Freyberg, J., Frentress, J., Penna, D., Dawson, T. E., \& Kirchner, J. W. (2018). Effects of climatic seasonality on the isotopic composition of evaporating soil waters. Hydrology and Earth System Sciences, 22(5), 2881-2890. https://doi.org/10.5194/hess-22-2881-2018

Bertrand, G., Masini, J., Goldscheider, N., Meeks, J., Lavastre, V., Celle-Jeanton, H., ... Hunkeler, D. (2014). Determination of spatiotemporal variability of tree water uptake using stable isotopes $\left(\delta^{18} \mathrm{O}, \delta^{2} \mathrm{H}\right)$ in an alluvial system supplied by a high-altitude watershed, Pfyn forest, Switzerland. Ecohydrology, 7(2), 319-333. https://doi.org/10.1002/eco.1347

Beyer, M., Hamutoko, J. T., Wanke, H., Gaj, M., \& Koeniger, P. (2018). Examination of deep root water uptake using anomalies of soil water stable isotopes, depth-controlled isotopic labeling and mixing models. Journal of Hydrology, 566, 122-136. https://doi.org/10.1016/j.jhydrol.2018.08.060

Bowling, D. R., Schulze, E. S., \& Hall, S. J. (2017). Revisiting streamside trees that do not use stream water: can the two water worlds hypothesis and snowpack isotopic effects explain a missing water source? Ecohydrology, 10(1), 1-12. https://doi.org/10.1002/eco.1771

Brinkmann, N., Seeger, S., Weiler, M., Buchmann, N., Eugster, W., \& Kahmen, A. (2018). Employing stable isotopes to determine the residence times of soil water and the temporal origin of water taken up by Fagus sylvatica and Picea abies in a temperate forest. New Phytologist, 219(4), 1300-1313. https://doi.org/10.1111/nph.15255

This article is protected by copyright. All rights reserved. 
Brooks, J. R., Barnard, H. R., Coulombe, R., \& McDonnell, J. J. (2010). Ecohydrologic separation of water between trees and streams in a Mediterranean climate. Nature Geoscience, 3(2), 100-104. https://doi.org/10.1038/ngeo722

Brunel, J. P., Walker, G. R., Dighton, J. C., \& Monteny, B. (1997). Use of stable isotopes of water to determine the origin of water used by the vegetation and to partition evapotranspiration. A case study from HAPEX-Sahel. Journal of Hydrology, 188-189, 466-481. https://doi.org/10.1016/S0022-1694(96)03188-5

Brunel, J. P., Walker, G. R., \& Kennett-Smith, A. K. (1995). Field validation of isotopic procedures for determining sources of water used by plants in a semi-arid environment. Journal of Hydrology, 167, 351-368. https://doi.org/10.1016/0022-1694(94)02575-V

Caldwell, M. M., Dawson, T. E., \& Richards, J. H. (1998). Hydraulic lift: consequences of water efflux from the roots of plants. Oecologia, 113(2), 151-161. https://doi.org/10.1007/s004420050363

Cappa, C. D., Hendricks, M. B., DePaolo, D. J., \& Cohen, R. C. (2003). Isotopic fractionation of water during evaporation. Journal of Geophysical Research, 108. https://doi.org/10.1029/2003JD003597

Cernusak, L. A., Winter, K., Aranda, J., \& Turner, B. L. (2008). Conifers, Angiosperm Trees, and Lianas: Growth, Whole-Plant Water and Nitrogen Use Efficiency, and Stable Isotope Composition $\left(\delta^{13} \mathrm{C}\right.$ and $\left.\delta^{18} \mathrm{O}\right)$ of Seedlings Grown in a Tropical Environment. Plant Physiology, 148(1), 642-659. https://doi.org/10.1104/pp.108.123521

Chi, Y., Zhou, L., Yang, Q., Li, S. peng, \& Zheng, S. (2019). Increased snowfall weakens complementarity of summer water use by different plant functional groups. Ecology and Evolution, 9(7), 4264-4274. https://doi.org/10.1002/ece3.5058

Choat, B., Jansen, S., Brodribb, T. J., Cochard, H., Delzon, S., Bhaskar, R., ... Zanne, A. E. (2012). Global convergence in the vulnerability of forests to drought. Nature, 491, 752755. https://doi.org/10.1038/nature11688

Croux, C., Haesbroeck, G. (1999). Influence Function and Efficiency of the Minimum Covariance Determinant Scatter Matrix Estimator. Journal of Multivariate Analysis, 71, 161-190. https://doi:10.1006/jmva.1999.1839

This article is protected by copyright. All rights reserved. 
Dansgaard, W. (1964). Stable isotopes in precipitation. Tellus, 16(4), 436-468. https://doi.org/10.1111/j.2153-3490.1964.tb00181.x

Davidson, E., Lefebvre, P. A., Brando, P. M., Ray, D. M., Trumbore, S. E., Solorzano, L. A., ... Nepstad, D. C. (2011). Carbon inputs and water uptake in deep soils of an eastern amazon forest. Forest Science, 57(1), 51-58. https://doi.org/10.1093/forestscience/57.1.51

Dubbert, M., Caldeira, M. C., Dubbert, D., \& Werner, C. (2019). A pool-weighted perspective on the two-water-worlds hypothesis. New Phytologist, 222(3), 1271-1283. https://doi.org/10.1111/nph.15670

Dubbert, M., Cuntz, M., Piayda, A., Maguás, C., \& Werner, C. (2013). Partitioning evapotranspiration - Testing the Craig and Gordon model with field measurements of oxygen isotope ratios of evaporative fluxes. Journal of Hydrology, 496, 142-153. https://doi.org/10.1016/j.jhydrol.2013.05.033

Ellsworth, P. Z., \& Sternberg, L. S. (2015). Seasonal water use by deciduous and evergreen woody species in a scrub community is based on water availability and root distribution. Ecohydrology, 8(4), 538-551. https://doi.org/10.1002/eco.1523

Evaristo, J., Jasechko, S., \& McDonnell, J. J. (2015). Global separation of plant transpiration from groundwater and streamflow. Nature, 525, 91-94. https://doi.org/10.1038/nature14983

Evaristo, J., Kim, M., Haren, J., Pangle, L. A., Harman, C. J., Troch, P. A., \& McDonnell, J. J. (2019). Characterizing the fluxes and age distribution of soil water, plant water, and deep percolation in a model tropical ecosystem. Water Resources Research. https://doi.org/10.1029/2018WR023265

Evaristo, J., \& McDonnell, J. J. (2017a). A role for meta-analysis in hydrology. Hydrological Processes, 31(20), 3588-3591. https://doi.org/10.1002/hyp.11253

Evaristo, J., \& McDonnell, J. J. (2017b). Prevalence and magnitude of groundwater use by vegetation: a global stable isotope meta-analysis. Scientific Reports, 7. https://doi.org/10.1038/srep44110 
February, E. C., \& Higgins, S. I. (2010). The distribution of tree and grass roots in savannas in relation to soil nitrogen and water. South African Journal of Botany, 76(3), 517-523. https://doi.org/10.1016/j.sajb.2010.04.001

Fox, J., Friendly, M., \& Monette, G. (2018). Package "heplots". Visualizing Hypothesis Tests in Multivariate Linear Models. Cran. Retrieved from http://datavis.ca/R/index.php\#heplots

Friendly, M., Monette, G., \& Fox, J. (2013). Elliptical Insights: Understanding statistical methods through elliptical geometry. Statistical Science, 28(1), 1-39. https://doi.org/10.1214/12-STS402

Gardner, W. R. (1960). Dynamic aspects of water availability to plants. Soil Science, 89(2), 63-73. Retrieved from https://journals.lww.com/soilsci/Citation/1960/02000

Gardner, W. R., \& Ehlig, C. F. (1963). The influence of soil water on transpiration by plants. Journal of Geophysical Research, 68(20), 5719-5724. https://doi.org/10.1029/JZ068i020p05719

Gat, J. R. (1996). Oxygen and hydrogen isotopes in the hydrologic cycle. Annual Review of Earth and Planetary Sciences, 24(1), 225-262. https://doi.org/10.1146/annurev.earth.24.1.225

Geris, J., Tetzlaff, D., McDonnell, J. J., \& Soulsby, C. (2017). Spatial and temporal patterns of soil water storage and vegetation water use in humid northern catchments. Science of The Total Environment, 595, 486-493. https://doi.org/10.1016/j.scitotenv.2017.03.275

Gibson, J. J., Birks, S. J., \& Edwards, T. W. D. (2008). Global prediction of $\delta$ A and $\delta 2 H-\delta 180$ evaporation slopes for lakes and soil water accounting for seasonality. Global Biogeochemical Cycles, 22(2). https://doi.org/10.1029/2007GB002997

Goldsmith, G. R., Allen, S. T., Braun, S., Engbersen, N., González-Quijano, C. R., Kirchner, J. W., \& Siegwolf, R. T. W. (2019). Spatial variation in throughfall, soil, and plant water isotopes in a temperate forest. Ecohydrology, 12(2), e2059. https://doi.org/10.1002/eco.2059

Goldsmith, G. R., Muñoz-Villers, L. E., Holwerda, F., McDonnell, J. J., Asbjornsen, H., \& Dawson, T. E. (2012). Stable isotopes reveal linkages among ecohydrological processes 
in a seasonally dry tropical montane cloud forest. Ecohydrology, 5(6), 779-790. https://doi.org/10.1002/eco.268

Goldstein, G., Meinzer, F. C., Bucci, S. J., Scholz, F. G., Franco, A. C., \& Hoffmann, W. A. (2008). Water economy of Neotropical savanna trees: Six paradigms revisited. Tree Physiology, 28(3), 395-404. https://doi.org/10.1093/treephys/28.3.395

Goller, R., Wilcke, W., Leng, M. J., Tobschall, H. J., Wagner, K., Valarezo, C., \& Zech, W. (2005). Tracing water paths through small catchments under a tropical montane rain forest in south Ecuador by an oxygen isotope approach. Journal of Hydrology, 308(1), 67-80. https://doi.org/10.1016/j.jhydrol.2004.10.022

Good, S. P., Noone, D., \& Bowen, G. (2015). Hydrologic connectivity constrains partitioning of global terrestrial water fluxes. Science, 349(6244), 175-177. https://doi.org/10.1126/science.aaa5931

Grossiord, C., Sevanto, S., Dawson, T. E., Adams, H. D., Collins, A. D., Dickman, L. T., ... Mcdowell, N. G. (2016). Warming combined with more extreme precipitation regimes modifies the water sources used by trees. New Phytologist, 213(2), 584-596. https://doi.org/10.1111/nph.14192

Gu, D., Zhang, Z., Mallik, A., Zhou, A., Mo, L., He, C., \& Huang, Y. (2015). Seasonal water use strategy of Cyclobalanopsis glauca in a karst area of southern China. Environmental Earth Sciences, 74(2), 1007-1014. https://doi.org/10.1007/s12665-014-3817-1

Hervé-Fernández, P., Oyarzun, C., Brumbt, C., Huygens, D., Bodé, S., Verhoest, N. E. C., \& Boeckx, P. (2016). Assessing the two water worlds hypothesis and water sources for native and exotic evergreen species in south-central Chile. Hydrological Processes, 30(23), 4227-4241. https://doi.org/10.1002/hyp.10984

Hetherington, A. M., \& Woodward, F. I. (2003). The role of stomata in sensing and driving environmental change. Nature, 424, 901-908. https://doi.org/10.1038/nature01843

Hijmans, R. J., Cameron, S. E., Parra, J. L., Jones, P. G., \& Jarvis, A. (2005). Very high resolution interpolated climate surfaces for global land areas. International Journal of Climatology, 25(15), 1965-1978. https://doi.org/10.1002/joc.1276

Hollander, M., \& Wolfe, D. A. (1999). Nonparametric Statistical Methods (2nd ed.). New York: John Wiley \& Sons, Inc.

This article is protected by copyright. All rights reserved. 
Jia, G., Liu, Z., Chen, L., \& Yu, X. (2017). Distinguish water utilization strategies of trees growing on earth-rocky mountainous area with transpiration and water isotopes. Ecology and Evolution, 7(24), 10640-10651. https://doi.org/10.1002/ece3.3584

Jobbágy, E. G., \& Jackson, R. B. (2001). The distribution of soil nutrients with depth: Global patterns and the imprint of plants. Biogeochemistry, 53(1), 51-77. https://doi.org/10.1023/A:1010760720215

Landwehr, J. M., \& Coplen, T. B. (2006). Line-conditioned excess: A new method for characterizing stable hydrogen and oxygen isotope ratios in hydrologic systems. In International Conference on Isotopes in Environmental Studies (pp. 132-135). IAEA Vienna. Retrieved from http://inis.iaea.org/search/search.aspx?orig_q=RN:36008379

Laurance, W. F. (2007). Forests and floods. Nature, 449, 409-410. https://doi.org/10.1038/449409a

Le Roux, X., Bariac, T., \& Mariotti, A. (1995). Spatial partitioning of the soil water resource between grass and shrub components in a West African humid savanna. Oecologia, 104(2), 147-155. https://doi.org/10.1007/BF00328579

Markewitz, D., Devine, S., Davidson, E. A., Brando, P., \& Nepstad, D. C. (2010). Soil moisture depletion under simulated drought in the Amazon: impacts on deep root uptake. New Phytologist, 187(3), 592-607. https://doi.org/10.1111/j.1469-8137.2010.03391.x

Martín-Gómez, P., Serrano, L., \& Ferrio, J. P. (2017). Short-term dynamics of evaporative enrichment of xylem water in woody stems: Implications for ecohydrology. Tree Physiology, 37(4), 511-522. https://doi.org/10.1093/treephys/tpw115

Matthews, A. J. (2017). Graph Data Extractor: A simple utility for graph data extraction. Version 2. Retrieved March 3, 2017, from https://sourceforge.net/projects/graphdataextrac/

Millar, C., Pratt, D., Schneider, D. J., \& McDonnell, J. J. (2018). A comparison of extraction systems for plant water stable isotope analysis. Rapid Communications in Mass Spectrometry, 32(13), 1031-1044. https://doi.org/10.1002/rcm.8136

Moore, J. W., \& Semmens, B. X. (2008). Incorporating uncertainty and prior information into stable isotope mixing models. Ecology Letters, 11(5), 470-480. https://doi.org/10.1111/j.1461-0248.2008.01163.x 
Nie, Y., Chen, H., Ding, Y., Zou, Q., Ma, X., \& Wang, K. (2019). Qualitative identification of hydrologically different water sources used by plants in rock-dominated environments. Journal of Hydrology, 573, 386-394. https://doi.org/10.1016/j.jhydrol.2019.03.097

Oerter, E. J., Siebert, G., Bowling, D. R., \& Bowen, G. (2019). Soil water vapour isotopes identify missing water source for streamside trees. Ecohydrology. https://doi.org/10.1002/eco.2083

Orlowski, N., Breuer, L., Angeli, N., Boeckx, P., Brumbt, C., Cook, C. S., .. McDonnell, J. J. (2018). Inter-laboratory comparison of cryogenic water extraction systems for stable isotope analysis of soil water. Hydrology and Earth System Sciences, 22(7), 3619-3637. https://doi.org/10.5194/hess-22-3619-2018

Parnell, A. C., Phillips, D. L., Bearhop, S., Semmens, B. X., Ward, E. J., Moore, J. W., ... Inger, R. (2013). Bayesian stable isotope mixing models. Environmetrics, 24(6), 387399. https://doi.org/10.1002/env.2221

Peel, M. C., Finlayson, B. L., \& McMahon, T. A. (2007). Updated world map of the KöppenGeiger climate classification. Hydrology and Earth System Sciences. https://doi.org/10.5194/hess-11-1633-2007

Penna, D., Hopp, L., Scandellari, F., Allen, S. T., Benettin, P., Beyer, M., ... Kirchner, J. W. (2018). Ideas and perspectives: Tracing terrestrial ecosystem water fluxes using hydrogen and oxygen stable isotopes - challenges and opportunities from an interdisciplinary perspective. Biogeosciences, 15(21), 6399-6415. https://doi.org/10.5194/bg-15-6399-2018

Phillips, D. L., \& Gregg, J. W. (2003). Source partitioning using stable isotopes: coping with too many sources. Oecologia, 136(2), 261-269. https://doi.org/10.1007/s00442-0031218-3

Phillips, S. L., \& Ehleringer, J. R. (1995). Limited uptake of summer precipitation by bigtooth maple (Acer grandidentatum Nutt) and Gambel's oak (Quereus gambelii Nutt). Trees, 9(4), 214-219. https://doi.org/10.1007/BF00195275

Pierret, A., Maeght, J.-L., Clément, C., Montoroi, J.-P., Hartmann, C., \& Gonkhamdee, S. (2016). Understanding deep roots and their functions in ecosystems: an advocacy for 
more unconventional research. Annals of Botany, 118(4), 621-635. https://doi.org/10.1093/aob/mcw130

Qiu, X., Zhang, M., Wang, S., Evaristo, J., Argiriou, A. A., Guo, R., ... Qu, D. (2019). The test of the ecohydrological separation hypothesis in a dry zone of the northeastern Tibetan Plateau. Ecohydrology, 12(3), e2077. https://doi.org/10.1002/eco.2077

Querejeta, J. I., Estrada-Medina, H., Allen, M. F., \& Jiménez-Osornio, J. J. (2007). Water source partitioning among trees growing on shallow karst soils in a seasonally dry tropical climate. Oecologia, 152(1), 26-36. https://doi.org/10.1007/s00442-006-0629-3

Restrepo-Coupe, N., da Rocha, H. R., Hutyra, L. R., da Araujo, A. C., Borma, L. S., Christoffersen, B., ... Saleska, S. R. (2013). What drives the seasonality of photosynthesis across the Amazon basin? A cross-site analysis of eddy flux tower measurements from the Brasil flux network. Agricultural and Forest Meteorology, 182183, 128-144. https://doi.org/10.1016/j.agrformet.2013.04.031

Retzlaff, W. A., Blaisdell, G. K., \& Topa, M. A. (2001). Seasonal changes in water source of four families of loblolly pine (Pinus taeda L.). Trees, 15(3), 154-162. https://doi.org/10.1007/s004680100087

Rosado, B. H. P., De Mattos, E. A., \& Sternberg, L. D. S. L. (2013). Are leaf physiological traits related to leaf water isotopic enrichment in restinga woody species? Anais Da Academia Brasileira de Ciências, 85, 1035-1045. https://doi.org/10.1590/S000137652013005000051

Rose, K. L., Graham, R. C., \& Parker, D. R. (2003). Water source utilization by Pinus jeffreyi and Arctostaphylos patula on thin soils over bedrock. Oecologia, 134(1), 46-54. https://doi.org/10.1007/s00442-002-1084-4

Rossatto, D. R., de Carvalho Ramos Silva, L., Villalobos-Vega, R., Sternberg, L. da S. L., \& Franco, A. C. (2012). Depth of water uptake in woody plants relates to groundwater level and vegetation structure along a topographic gradient in a neotropical savanna. Environmental and Experimental Botany, 77, 259-266. https://doi.org/10.1016/j.envexpbot.2011.11.025

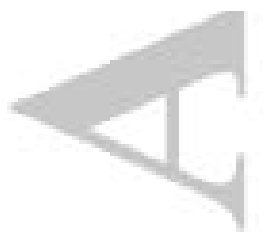


Rothfuss, Y., \& Javaux, M. (2017). Reviews and syntheses: Isotopic approaches to quantify root water uptake: a review and comparison of methods. Biogeosciences, 14(8), 21992224. https://doi.org/10.5194/bg-14-2199-2017

Rousseeuw, P. J., \& Van Driessen, K. (1999). A Fast Algorithm for the Minimum Covariance Determinant Estimator. Technometrics, 41(3), 212-223. https://doi.org/10.1080/00401706.1999.10485670

Saxton, K. E., \& Rawls, W. J. (2006). Soil water characteristic estimates by texture and organic matter for hydrologic solutions. Soil Science Society of America Journal, 70(5), 1569. https://doi.org/10.2136/sssaj2005.0117

Scandellari, F., \& Penna, D. (2017). Gli isotopi stabili nell'acqua fra suolo, pianta e atmosfera. Italus Hortus, 24(2), 51-67. https://doi.org/10.26353/j.itahort/2017.2.5167

Schlaepfer, D. R., Ewers, B. E., Shuman, B. N., Williams, D. G., Frank, J. M., Massman, W. J., \& Lauenroth, W. K. (2014). Terrestrial water fluxes dominated by transpiration: Comment. Ecosphere, 5(5), 1-9. https://doi.org/10.1890/ES13-00391.1

Schlesinger, W. H., \& Jasechko, S. (2014). Transpiration in the global water cycle. Agricultural and Forest Meteorology, 189-190, 115-117. https://doi.org/10.1016/j.agrformet.2014.01.011

Schneider, A. (2017). GPS Visualizer: On-line utility that creates maps and profiles from geographic data. Retrieved from http://www.gpsvisualizer.com/

Schoonover, J. E., \& Crim, J. F. (2015). An Introduction to soil concepts and the role of soils in watershed management. Journal of Contemporary Water Research and Education, 154(1), 21-47. https://doi.org/10.1111/j.1936-704X.2015.03186.x

Schwendenmann, L., Pendall, E., Sanchez-Bragado, R., Kunert, N., \& Hölscher, D. (2015). Tree water uptake in a tropical plantation varying in tree diversity: interspecific differences, seasonal shifts and complementarity. Ecohydrology, 8(1), 1-12. https://doi.org/10.1002/eco.1479

Singleton, M. J., Sonnenthal, E. L., Conrad, M. E., DePaolo, D. J., \& Gee, G. W. (2004). Multiphase reactive transport modeling of seasonal infiltration events and stable isotope fractionation in unsaturated zone pore water and vapor at the Hanford Site. Vadose Zone Journal, 3, 775-785. https://doi.org/10.2136/vzj2004.0775 
Sprenger, M., Stumpp, C., Weiler, M., Aeschbach, W., Allen, S. T., Benettin, P., et al. (2019). The demographics of water: A review of water ages in the critical zone. Reviews of Geophysics, 57. https://doi.org/10.1029/2018RG000633

Sprenger, M., Leistert, H., Gimbel, K., \& Weiler, M. (2016). Illuminating hydrological processes at the soil-vegetation atmosphere interface with water stable isotopes. Reviews of Geophysics, (54). https://doi.org/10.1002/ 2015RG000515

Stoll, M. (2014). H and O stable isotope compositions of different soil water types - effect of soil properties. Swedish University of Agricultural sciences.

The Plant list (2013). A working list of all plant species. Version 1.1. Retrieved from http://www.theplantlist.org/

Thorburn, P. J., \& Walker, G. R. (1993). The source of water transpired by Eucalyptus camaldulensis: soil, groundwater, or streams? In J. R. Ehleringer, A. E. Hall, \& G. D. Farquhar (Eds.), Stable Isotopes and Plant Carbon-water Relations (pp. 511-527). San Diego: Academic Press. https://doi.org/10.1016/B978-0-08-091801-3.50042-8

Trabucco, A., \& Zomer, R. J. (2009). Global Potential Evapo-Transpiration (Global-PET) and Global Aridity Index (Global-Aridity) Geo-Database. Retrieved from http://www.csi.cgiar.org

UNEP (United Nations Environment Programme). (1997). World atlas of desertification 2ED.

Van Aelst, S., \& Rousseeuw, P. (2009). Minimum volume ellipsoid. Wiley Interdisciplinary Reviews: Computational Statistics, 1(1), 71-82. https://doi.org/10.1002/wics.19

Wei, Y. F., Fang, J., Liu, S., Zhao, X. Y., \& Li, S. G. (2013). Stable isotopic observation of water use sources of Pinus sylvestris var. mongolica in Horqin Sandy Land, China. Trees, 27(5), 1249-1260. https://doi.org/10.1007/s00468-013-0873-1

Weltzin, J. F., \& McPherson, G. R. (1997). Spatial and temporal soil moisture resource partitioning by trees and grasses in a temperate savanna, Arizona, USA. Oecologia, 112(2), 156-164. https://doi.org/10.1007/s004420050295

Werner, C., Schnyder, H., Cuntz, M., Keitel, C., Zeeman, M. J., Dawson, T. E., ... Gessler, A. (2012). Progress and challenges in using stable isotopes to trace plant carbon and water relations across scales. Biogeosciences, 9(8), 3083-3111. https://doi.org/10.5194/bg-93083-2012

This article is protected by copyright. All rights reserved. 
West, A. G., Hultine, K. R., Burtch, K. G., \& Ehleringer, J. R. (2007). Seasonal variations in moisture use in a piñon-juniper woodland. Oecologia, 153(4), 787-798. https://doi.org/10.1007/s00442-007-0777-0

Williams, D. G., \& Ehleringer, J. R. (2000). Intra- and interspecific variation for summer precipitation use in pinyon-juniper woodlands. Ecological Monographs, 70(4), 517-537. https://doi.org/10.2307/2657185

Wu, J., Albert, L. P., Lopes, A. P., Restrepo-Coupe, N., Hayek, M., Wiedemann, K. T., ... Saleska, S. R. (2016). Leaf development and demography explain photosynthetic seasonality in Amazon evergreen forests. Science, 351(6276), 972 LP-976. https://doi.org/10.1126/science.aad5068

Yang, Y., \& Fu, B. (2017). Soil water migration in the unsaturated zone of semiarid region in China from isotope evidence. Hydrology and Earth System Sciences, 21(3), 1757-1767. https://doi.org/10.5194/hess-21-1757-2017

Zhang, X., Xiao, Y., Wan, H., Deng, Z., Pan, G., \& Xia, J. (2017). Using stable hydrogen and oxygen isotopes to study water movement in soil-plant-atmosphere continuum at Poyang Lake wetland, China. Wetlands Ecology and Management, 25(2), 1-14. https://doi.org/10.1007/s11273-016-9511-1

Zhao, Y., \& Wang, L. (2018). Plant water use strategy in response to spatial and temporal variation in precipitation patterns in China: A stable isotope analysis. Forests, 9(3), 121. https://doi.org/10.3390/f9030123

Zhu, L., Wang, Z. H., Mao, G. L., Zheng, S. X., \& Xu, X. (2014). Water uptake from different soil depths for halophytic shrubs grown in Northern area of Ningxia plain (China) in contrasted water regimes. Journal of Plant Interactions, 9(1), 26-34. https://doi.org/10.1080/17429145.2012.751139

Zhu, L., Zhang, H., Gao, X., Qi, Y., \& Xu, X. (2016). Seasonal patterns in water uptake for Medicago sativa grown along an elevation gradient with shallow groundwater table in Yanchi county of Ningxia, Northwest China. Journal of Arid Land, 8(6), 921-934. https://doi.org/10.1007/s40333-016-0017-8 
Table 1. Median d-excess (\%) of xylem water and soil water for different plant groups and soil water depths in different climate zones. Number of samples are reported in parentheses.

\begin{tabular}{|l|l|l|l|l|}
\hline & Tropical & Arid & Temperate & Cold \\
\hline Xylem water & & & & \\
\hline Angiosperms & $4.3(407)$ & $-4.1(196)$ & $-1.4(625)$ & $-6.4(395)$ \\
\hline Gymnosperms & - & $-16.7(112)$ & $0.5(587)$ & $-0.7(197)$ \\
\hline Soil water & & & & \\
\hline $\mathbf{0 - 1 0} \mathbf{~ c m}$ & $6.1(294)$ & $-27.6(39)$ & $-2.7(583)$ & $-1.5(236)$ \\
\hline $\mathbf{1 0 - 3 0 ~ c m}$ & $8.9(296)$ & $-18.4(70)$ & $3.1(387)$ & $1.1(393)$ \\
\hline $\mathbf{3 0 - 5 0} \mathbf{~ c m}$ & $9.4(281)$ & $-10.0(54)$ & $6.3(511)$ & $4.1(231)$ \\
\hline$>\mathbf{5 0}$ cm & $9.3(323)$ & $-2.6(94)$ & $7.6(335)$ & $4.4(684)$ \\
\hline
\end{tabular}


Table 2. Spearman rank correlation coefficient for the relation between characteristics of the study sites and $\delta^{18} \mathrm{O}, \delta^{2} \mathrm{H}$ and d-excess of soil water (no. of soil water samples=5328). All the correlations are significant $(\mathrm{p}<0.001)$.

\begin{tabular}{|l|l|l|l|}
\hline & $\boldsymbol{\delta}^{\mathbf{1 8}} \mathbf{O}(\mathbf{\%})$ & $\boldsymbol{\delta}^{\mathbf{2}} \mathbf{H}(\mathbf{\%})$ & d-excess (\%o) \\
\hline MAT ( $\left.{ }^{\circ} \mathbf{C}\right)$ & 0.58 & 0.67 & 0.16 \\
\hline Elevation (m a.s.l.) & -0.38 & & \\
\hline & & & -0.15 \\
\hline
\end{tabular}


Table 3. Spearman rank correlation coefficient for the relation between characteristics of the study sites and $\delta^{18} \mathrm{O}, \delta^{2} \mathrm{H}$ and d-excess of xylem water (no. of xylem water samples=2579). All the correlations are significant $(\mathrm{p}<0.001)$.

\begin{tabular}{|c|c|c|c|}
\hline 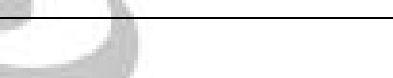 & $\delta^{18} \mathrm{O}(\%)$ & $\delta^{2} H(\%)$ & d-excess (\%o) \\
\hline MAT $\left({ }^{\circ} \mathbf{C}\right)$ & 0.65 & 0.73 & 0.28 \\
\hline Elevation (m a.s.l. & -0.39 & -0.49 & -0.27 \\
\hline Global aridity index & 0.12 & 0.25 & 0.35 \\
\hline
\end{tabular}


Table 4. Percentage of papers based on water extraction techniques.

\begin{tabular}{|c|c|c|c|c|c|c|}
\hline Extraction & No. of & Percentage $(\%)$ & \multicolumn{4}{|c|}{ No. of samples per climate zone* } \\
\hline technique & papers & of papers & Tropical & Arid & Temperate & Cold \\
\hline $\begin{array}{l}\text { Azeotropic } \\
\text { distillation }\end{array}$ & 8 & 12.1 & 0 & 187 & 257 & 200 \\
\hline $\begin{array}{l}\text { Cryogenic } \\
\text { vacuum } \\
\text { distillation }\end{array}$ & 56 & 84.8 & 1726 & 504 & 2937 & 1724 \\
\hline $\begin{array}{l}\text { Liquid-vapor } \\
\text { equilibration }\end{array}$ & 1 & 1.5 & 0 & 0 & 0 & 254 \\
\hline Pressure chamber & 1 & 1.5 & 0 & 0 & 86 & 0 \\
\hline
\end{tabular}

*The number of samples reported in the table are the sum of both xylem water and soil water samples. 


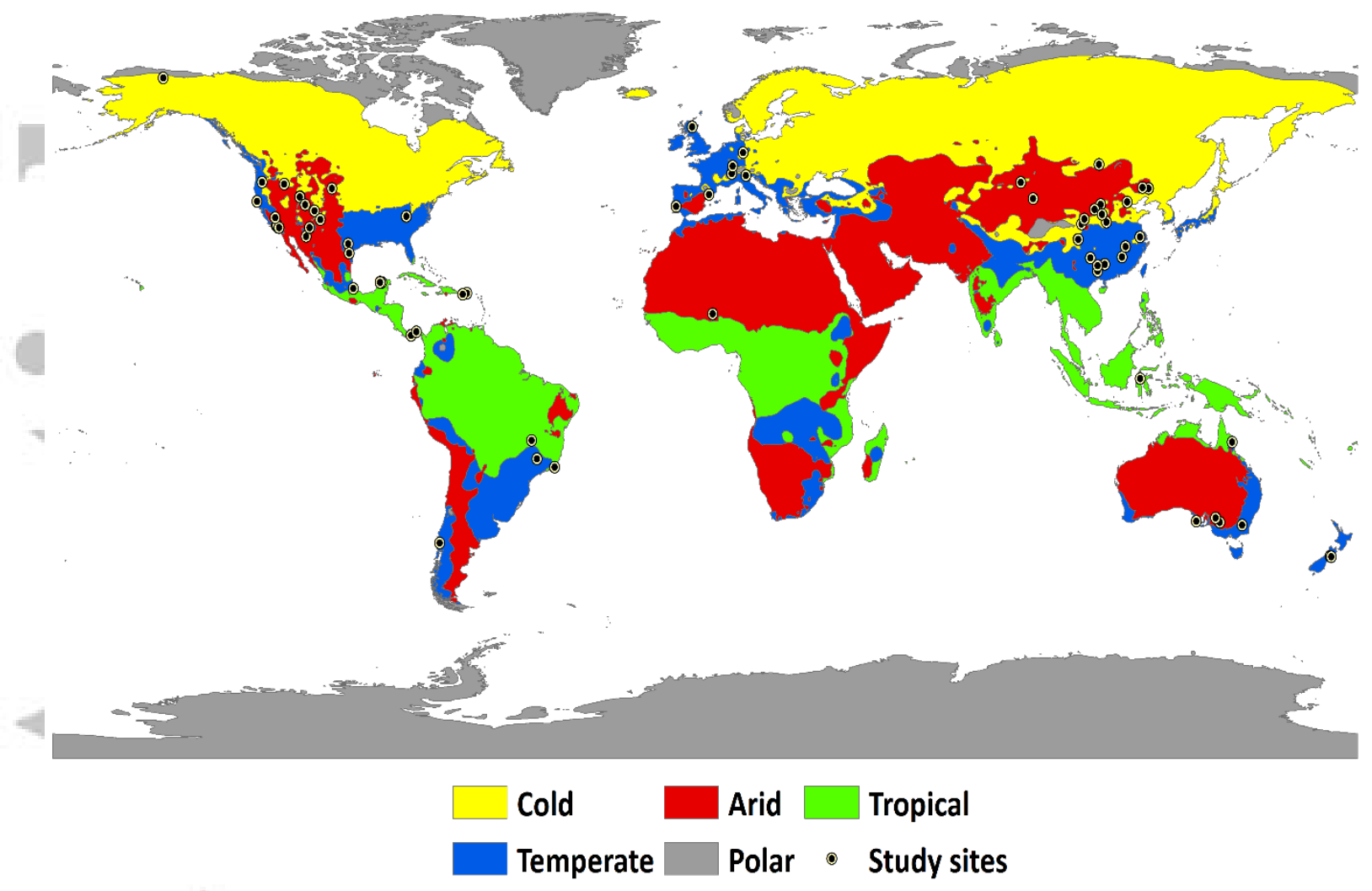

Figure 1. Köppen climate classification (Peel, Finlayson, \& McMahon, 2007) for all study sites included in this global analysis.

This article is protected by copyright. All rights reserved. 

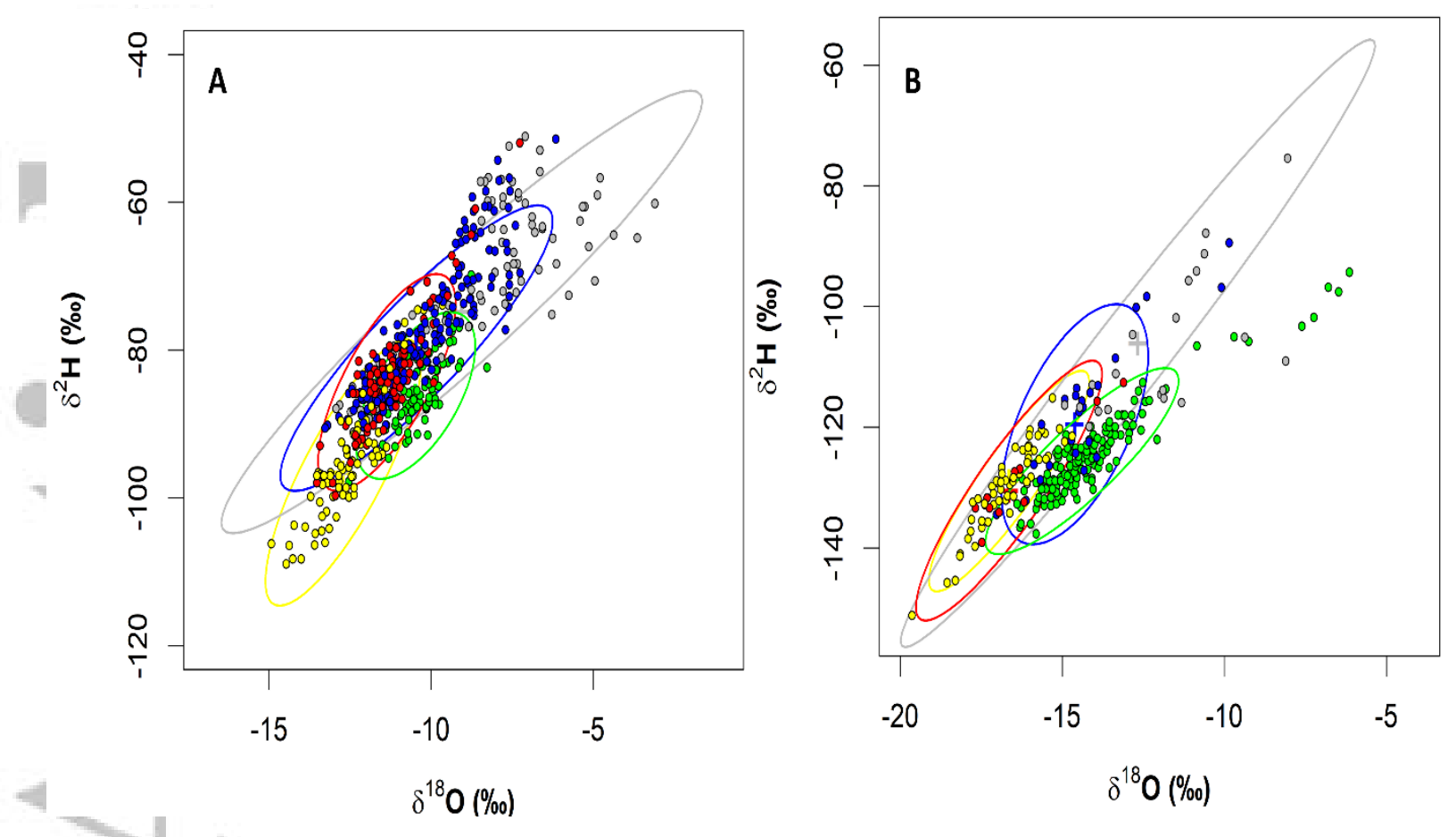

Figure 2. Examples of the computation of the degree of overlap between xylem water (green 99\% confidence ellipse), 0-10 cm soil water (grey ellipse), 10-30 cm soil water (blue ellipse), $30-50 \mathrm{~cm}$ soil water (red ellipse) and $>50 \mathrm{~cm}$ soil water (yellow ellipse) plotted in the dual isotope space. Study site A (left panel, xylem water: $\mathrm{n}=93$; 0-10 cm: $\mathrm{n}=85,10-30 \mathrm{~cm}$ : $\mathrm{n}=160$; 30-50 cm: $\mathrm{n}=85$, and $>50 \mathrm{~cm}: \mathrm{n}=77$ ) and study site $\mathrm{B}$ (right panel, xylem water: $\mathrm{n}=137 ; 0-10$ cm: $\mathrm{n}=21,10-30 \mathrm{~cm}: \mathrm{n}=24 ; 30-50 \mathrm{~cm}: \mathrm{n}=19$, and $>50 \mathrm{~cm}: \mathrm{n}=58)$ respectively. 


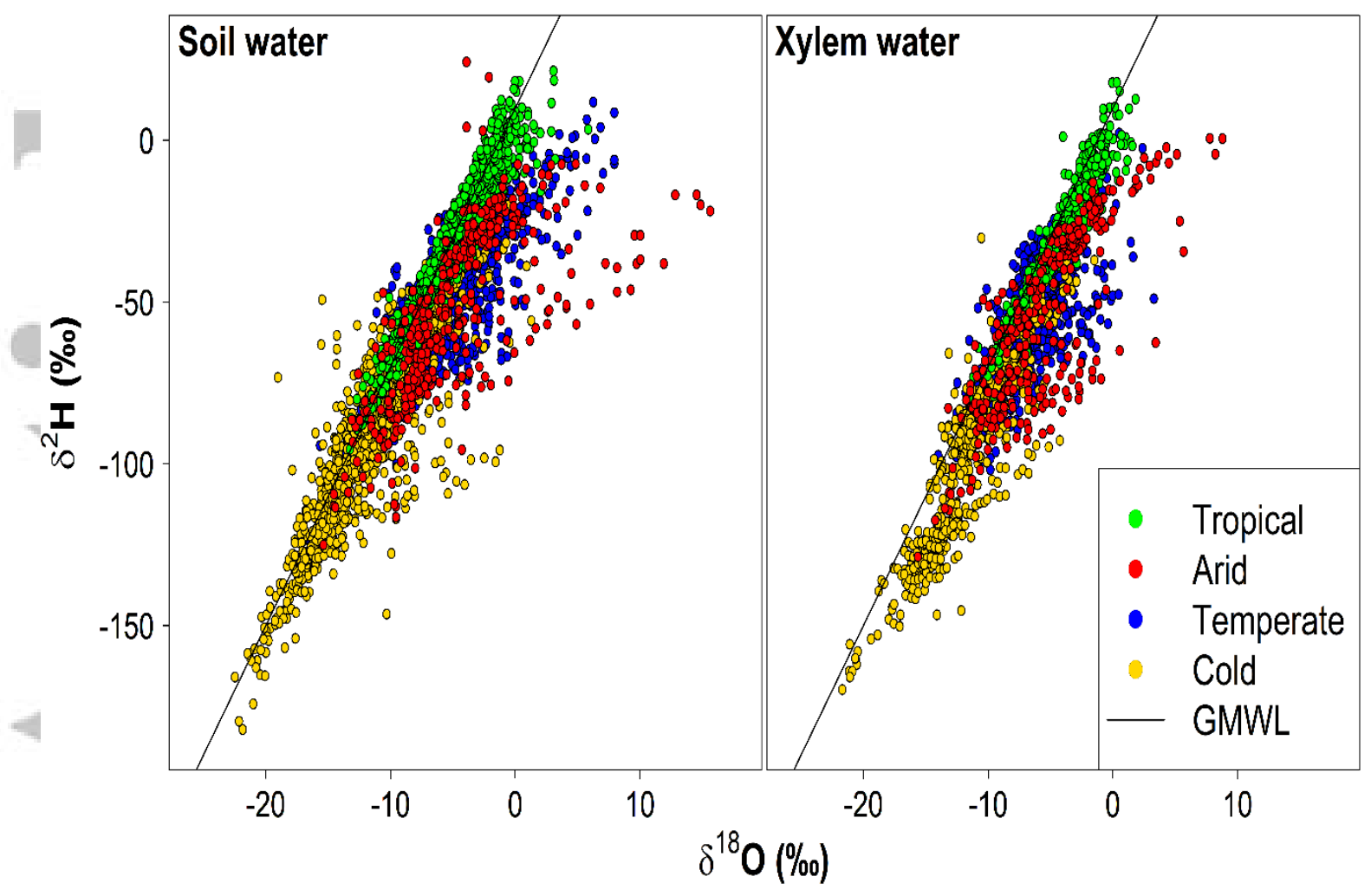

Figure 3. Dual-isotope plot of soil water (tropical, $n=1284$; arid, $n=383$; temperate, $n=2075$; cold, $\mathrm{n}=1586$ ) and xylem water (tropical, $\mathrm{n}=442$; arid, $\mathrm{n}=308$; temperate, $\mathrm{n}=1237$; cold, $\mathrm{n}=592$ ) samples in different climate zones according to Köppen climate classification. 


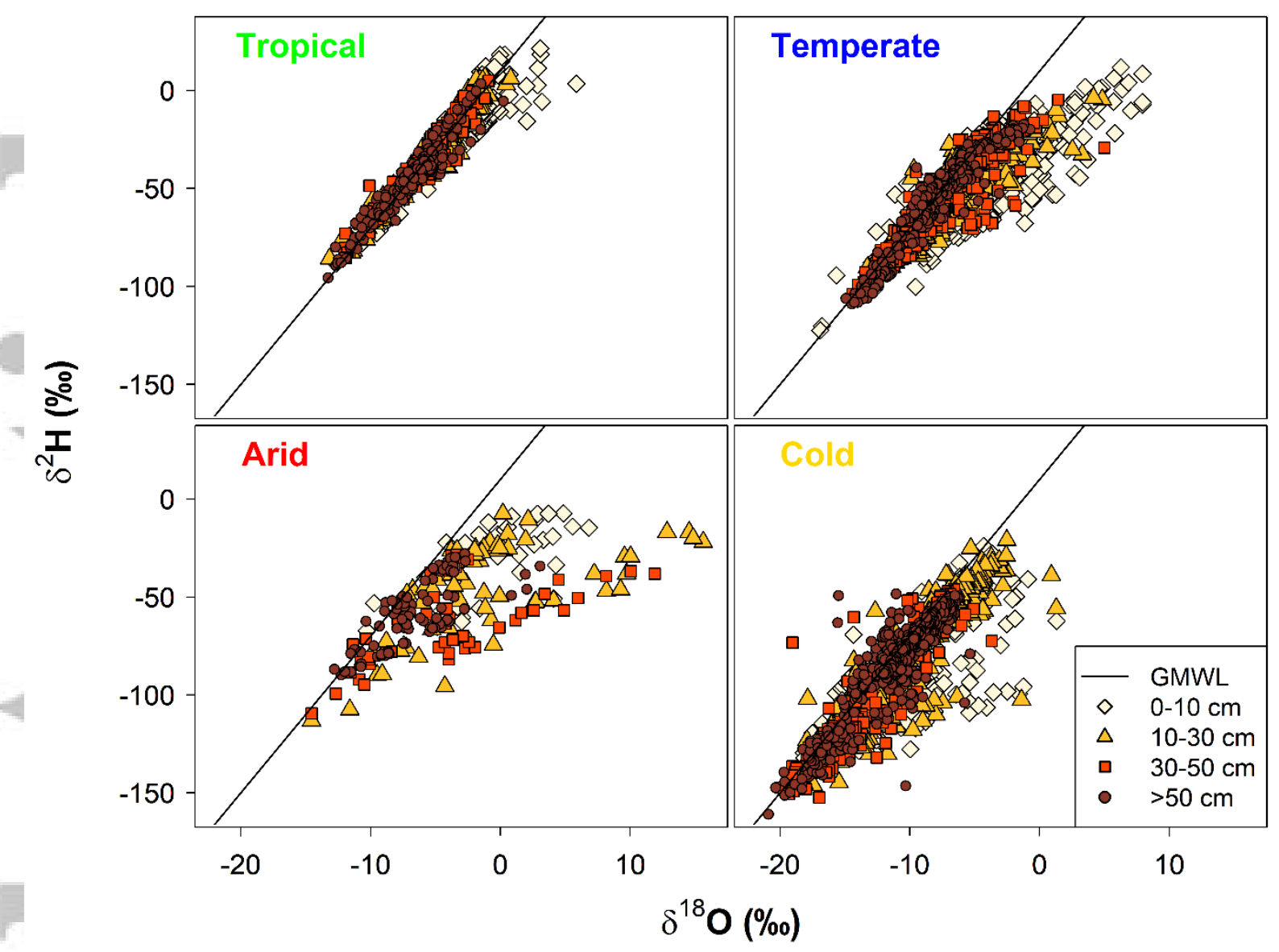

Figure 4. Dual-isotope plot of soil water at different depths in different climates, i.e. tropical (0-10 cm, $\mathrm{n}=294 ; 10-30 \mathrm{~cm}, \mathrm{n}=296 ; 30-50 \mathrm{~cm}, \mathrm{n}=281 ;>50 \mathrm{~cm}, \mathrm{n}=323)$, arid $(0-10 \mathrm{~cm}, \mathrm{n}=39$; $10-30 \mathrm{~cm}, \mathrm{n}=70 ; 30-50 \mathrm{~cm}, \mathrm{n}=54 ;>50 \mathrm{~cm}, \mathrm{n}=94)$, temperate $(0-10 \mathrm{~cm}, \mathrm{n}=583 ; 10-30 \mathrm{~cm}$, $\mathrm{n}=387 ; 30-50 \mathrm{~cm}, \mathrm{n}=511 ;>50 \mathrm{~cm}, \mathrm{n}=335)$ and cold zone $(0-10 \mathrm{~cm}, \mathrm{n}=236 ; 10-30 \mathrm{~cm}, \mathrm{n}=393$; $30-50 \mathrm{~cm}, \mathrm{n}=231 ;>50 \mathrm{~cm}, \mathrm{n}=684)$.

This article is protected by copyright. All rights reserved. 
A

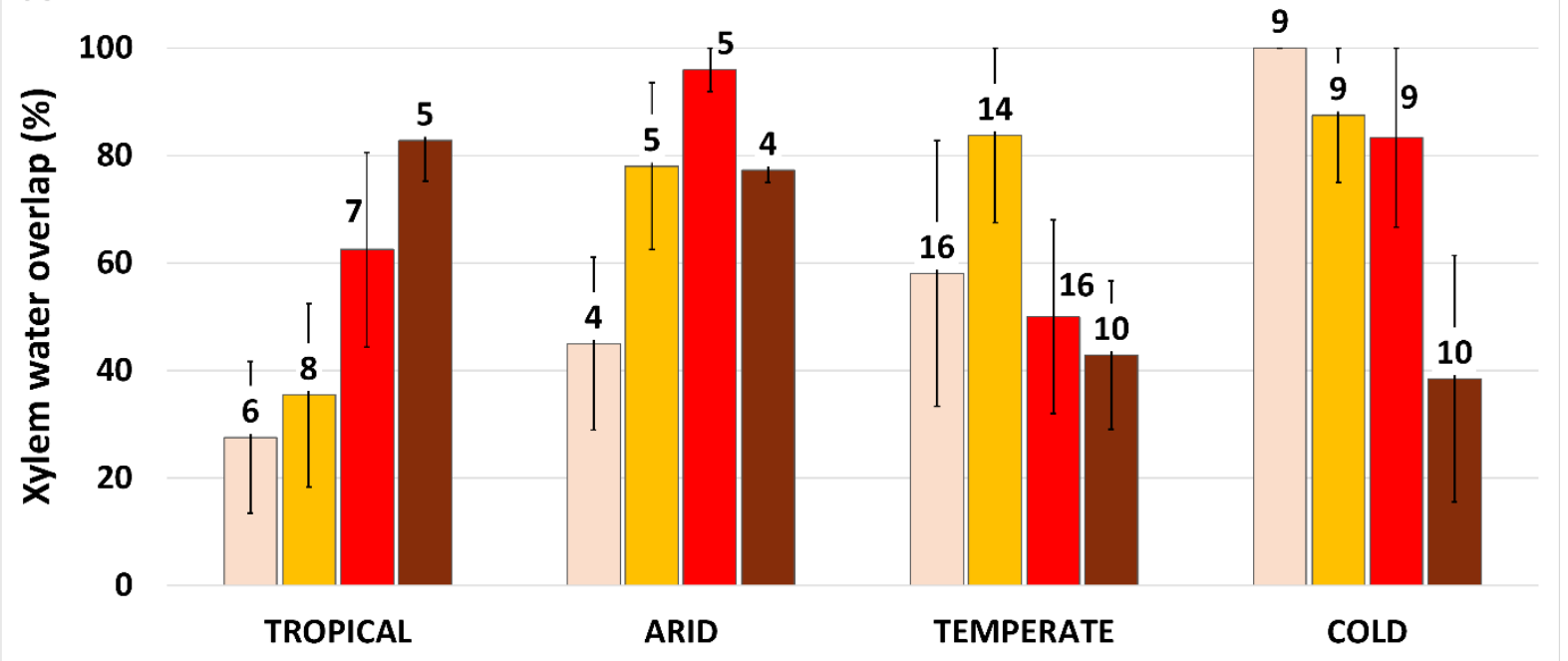

B

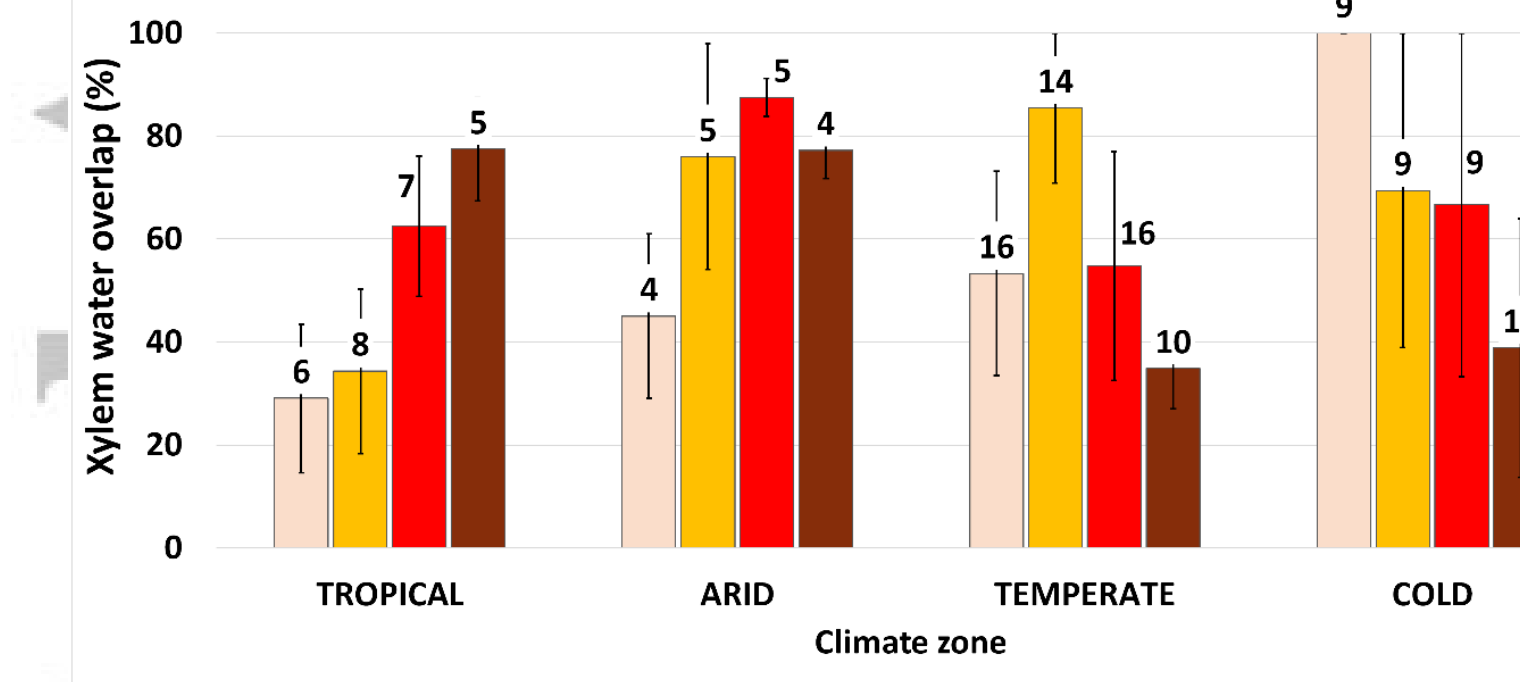

TROPICAL
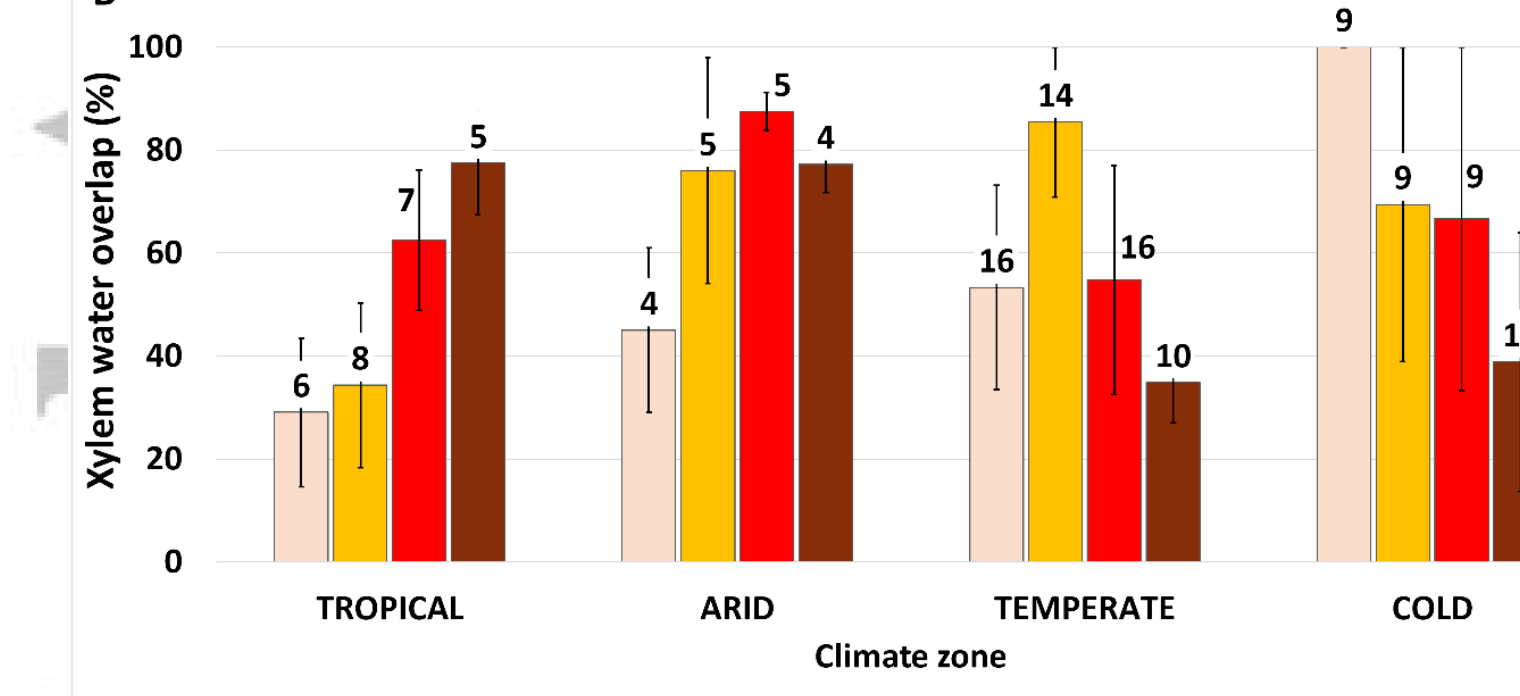

9

$\square 0-10 \mathrm{~cm} \quad \square 10-30 \mathrm{~cm} \quad \square 30-50 \mathrm{~cm} \quad \square>50 \mathrm{~cm}$

\begin{tabular}{l|ccccc} 
Climate zone & $\begin{array}{c}\text { No. of } \\
\text { xylem } \\
\text { samples }\end{array}$ & $\begin{array}{c}\text { No. of soil } \\
\text { samples } \\
\text { at } \mathbf{0 - 1 0} \mathbf{~ c m}\end{array}$ & $\begin{array}{c}\text { No. of soil } \\
\text { samples at } \\
\mathbf{1 0 - 3 0} \mathbf{~ c m}\end{array}$ & $\begin{array}{c}\text { No. of soil } \\
\text { samples at } \\
\mathbf{3 0 - 5 0} \mathbf{~ c m}\end{array}$ & $\begin{array}{c}\text { No. of soil } \\
\text { samples }>\mathbf{5 0} \mathbf{~ c m}\end{array}$ \\
\hline TROPICAL & 406 & 289 & 296 & 287 & 321 \\
ARID & 254 & 36 & 67 & 51 & 85 \\
\hline TEMPERATE & 1105 & 577 & 380 & 506 & 329 \\
COLD & 437 & 233 & 391 & 227 & 688
\end{tabular}

Figure 5. Median overlap (\%) of xylem water with soil water at different depths $(0-10 \mathrm{~cm}, 10-$ $30 \mathrm{~cm}, 30-50 \mathrm{~cm}$ and $>50 \mathrm{~cm}$ ) in different climate zones. The number of samples considered for each climate zone is shown in a table given below the bar plot. The number reported above each bar indicates the number of study sites. Error bars represent median absolute deviations. Robust covariance ellipses by using two methods for outliers detection: A) minimum covariance determinant (MCD), B) minimum volume ellipsoid (MVE). 


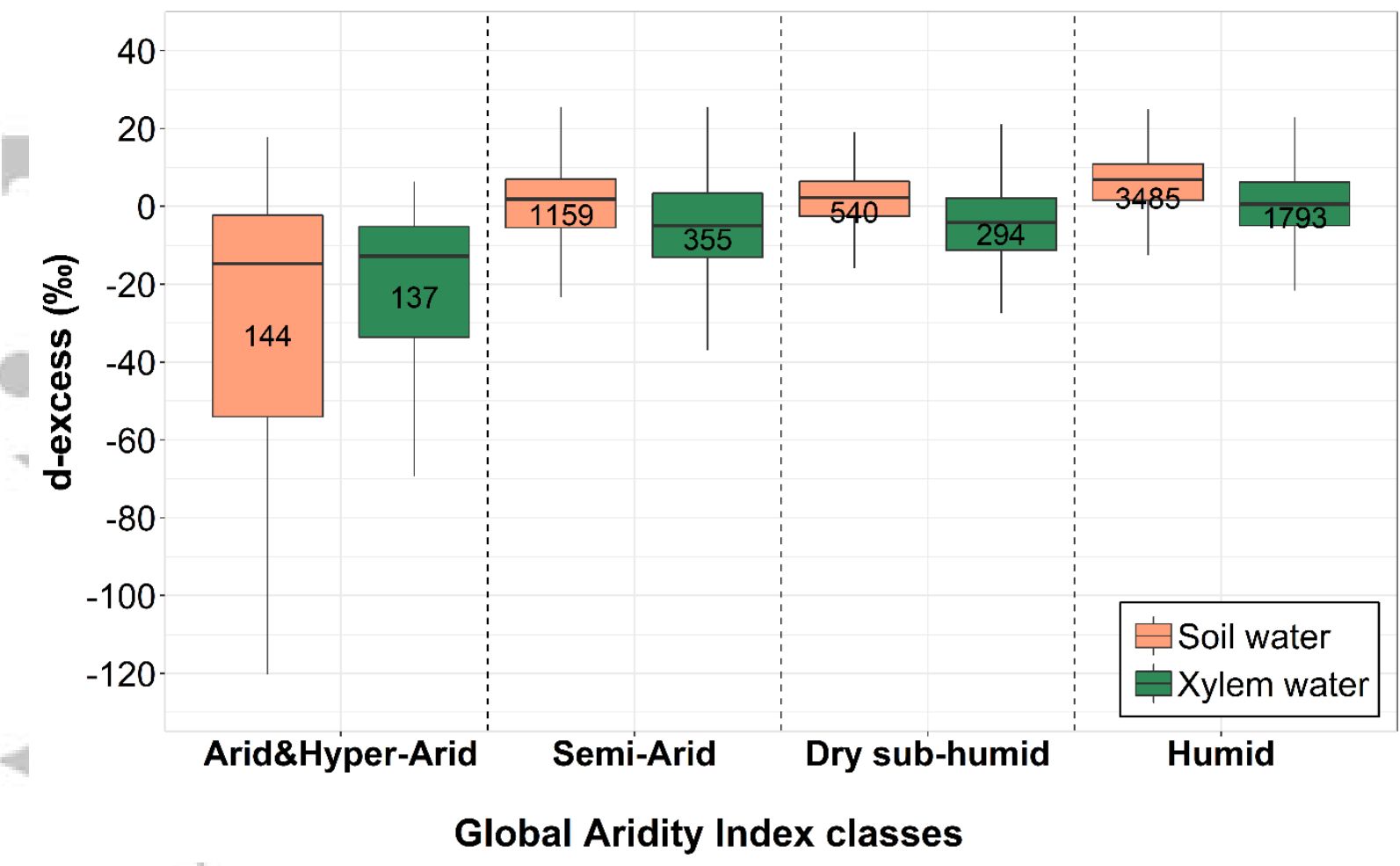

Figure 6. Boxplots of soil water and xylem water d-excess grouped as a function of Global Aridity Index classes (Aridity Index (UNEP, 1997); aridity index values increase for more humid conditions and decrease with more arid conditions). Boxes represent the 25th and 75th percentiles, while whiskers indicate the minimum and maximum values excluding the outliers. The number inside each box indicates the sample size. The horizontal solid line within boxes represents the median. 


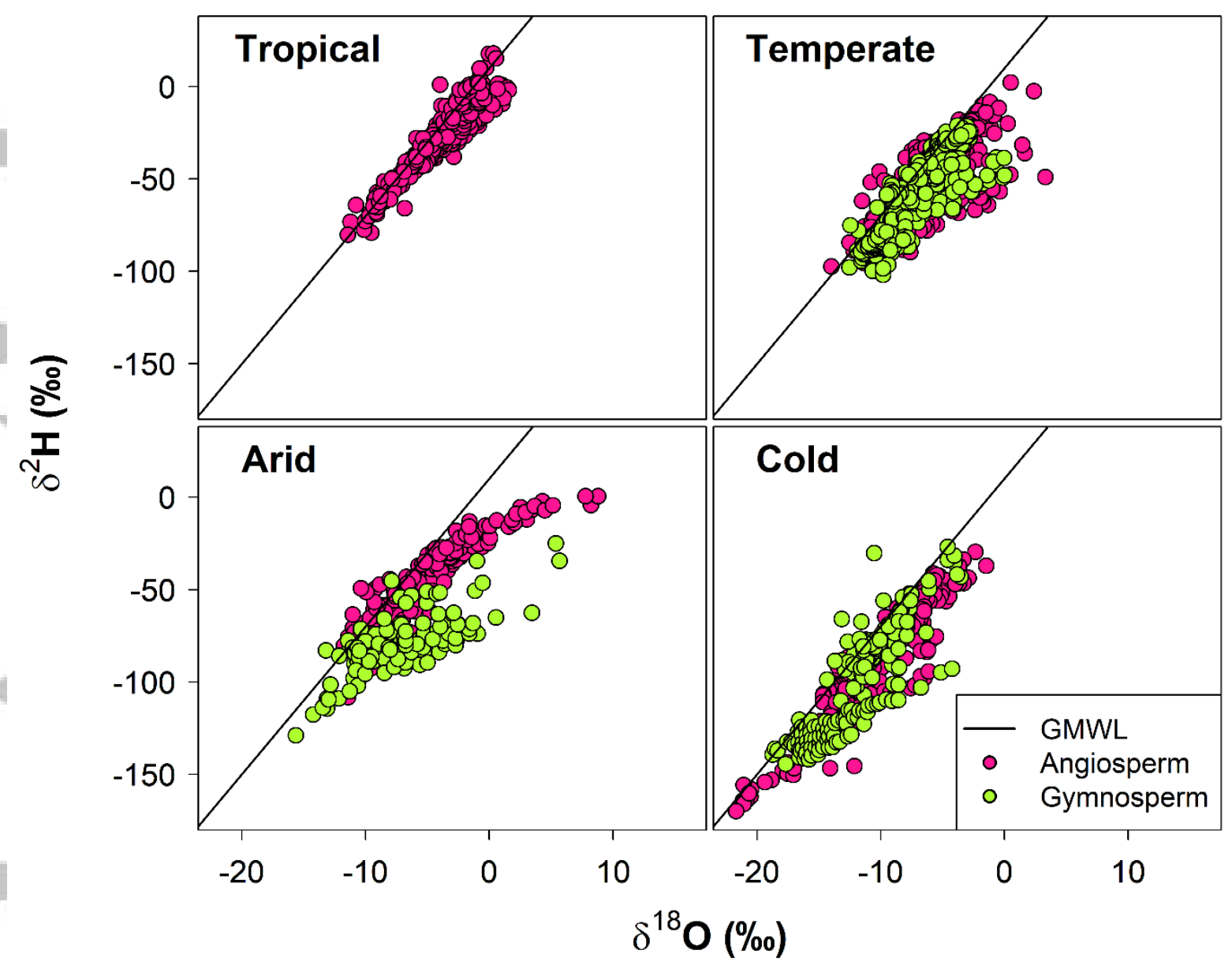

Figure 7. Dual-isotope plot of xylem water for different plant groups in the different climate zones. Tropical zone, angiosperms: $n=407$. Temperate zone, angiosperms: $n=625$; gymnosperms: n=587. Arid zone, angiosperms: n=196; gymnosperms: n=112. Cold zone, angiosperms: $n=395$; gymnosperms: $n=197$.

This article is protected by copyright. All rights reserved. 